
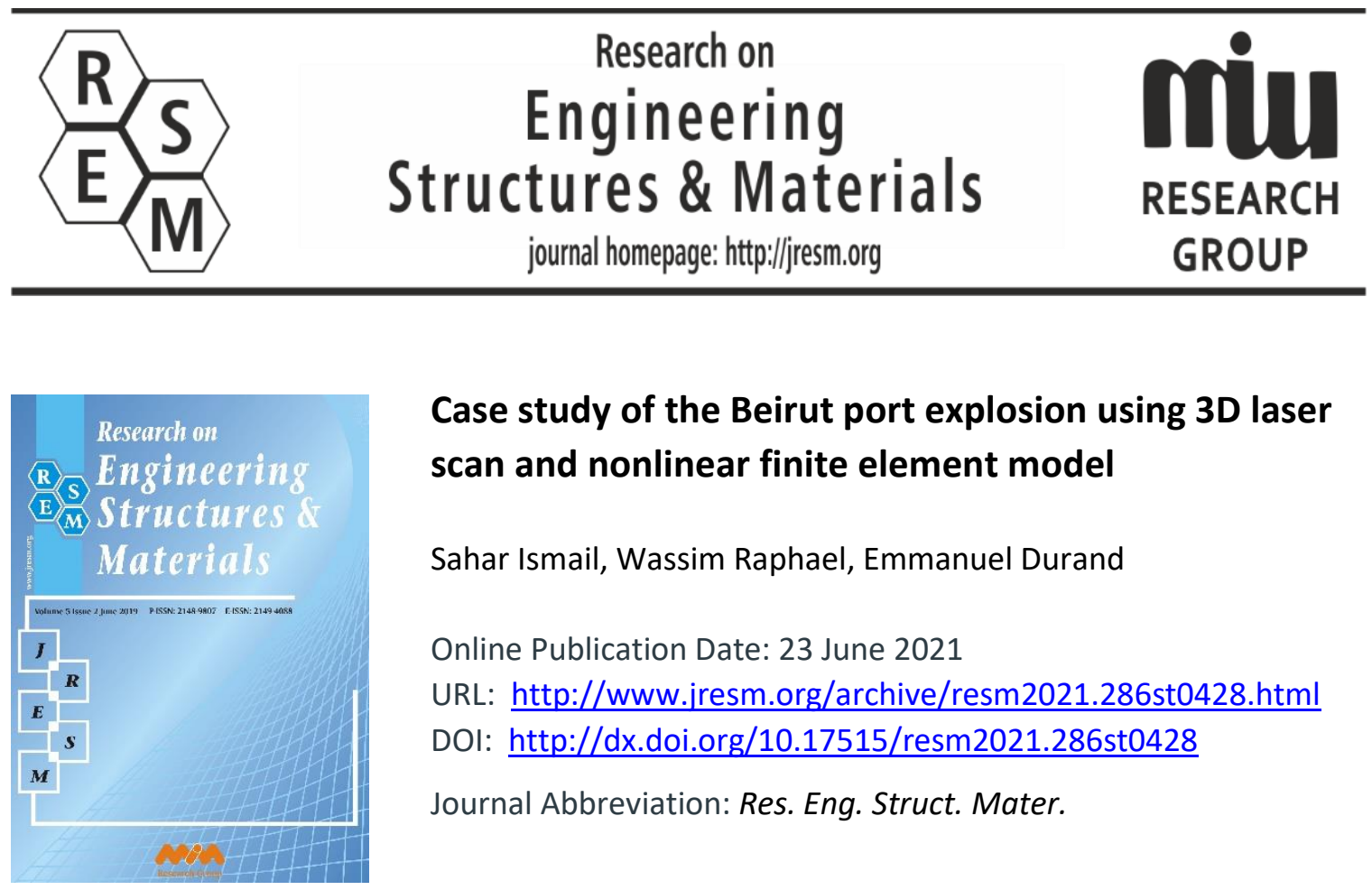

\title{
Case study of the Beirut port explosion using 3D laser scan and nonlinear finite element model
}

Sahar Ismail, Wassim Raphael, Emmanuel Durand

Online Publication Date: 23 June 2021

URL: http://www.jresm.org/archive/resm2021.286st0428.html

DOI: http://dx.doi.org/10.17515/resm2021.286st0428

Journal Abbreviation: Res. Eng. Struct. Mater.

\section{To cite this article}

Ismail S, Raphael W, Durand E. Case study of the Beirut port explosion using 3D laser scan and nonlinear finite element model. Res. Eng. Struct. Mater., 2021; 7(4): 551-577.

\section{Disclaimer}

All the opinions and statements expressed in the papers are on the responsibility of author(s) and are not to be regarded as those of the journal of Research on Engineering Structures and Materials (RESM) organization or related parties. The publishers make no warranty, explicit or implied, or make any representation with respect to the contents of any article will be complete or accurate or up to date. The accuracy of any instructions, equations, or other information should be independently verified. The publisher and related parties shall not be liable for any loss, actions, claims, proceedings, demand or costs or damages whatsoever or howsoever caused arising directly or indirectly in connection with use of the information given in the journal or related means.

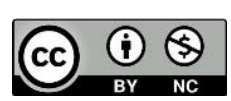

Published articles are freely available to users under the terms of Creative Commons Attribution - NonCommercial 4.0 International Public License, as currently displayed at here (the "CC BY - NC"). 


\title{
Research on Engineering Structures \& Materials
}

journal homepage: http://jresm.org

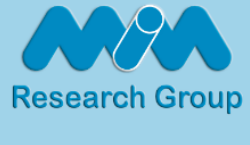

Research Article

\section{Case study of the Beirut port explosion using 3D laser scan and nonlinear finite element model}

\author{
Sahar Ismail ${ }^{* 1, a}$, Wassim Raphael ${ }^{1, b}$, Emmanuel Durand ${ }^{2, c}$ \\ ${ }^{1}$ Department of Civil Engineering, the Higher School of Engineering ESIB, Saint Joseph University of Beirut, \\ Lebanon \\ ${ }^{2}$ Amann Engineering, Geneva, Switzerland
}

\begin{tabular}{l} 
Article Info \\
Article history: \\
Received 28 Apr 2021 \\
Revised 21 Jun 2021 \\
Accepted 22 Jun 2021 \\
\hline Keywords: \\
Blast loading; \\
Concrete damage \\
plasticity; \\
Concrete failure; \\
Finite element analysis
\end{tabular}

\section{Abstract}

Analysis of the structural failure of the Beirut port silos by the August 4, 2020 explosion is presented in this paper. The structural response of the silos due to the blast loading imposed by the explosion was assessed using 3D laser scan. Then, the silos were modeled using three-dimensional finite element models using Abaqus explicit. The silos' damage and failure were investigated to estimate the blast magnitude and to check the silos structural response against the silos' concrete strength and additional reinforcement and concrete coating added to the silos in 2000. In addition to the effects of reinforcing the ribs between the silos as well as the soil and foundation. Therefore, these parameters were tested after estimating the blast magnitude to check the structural status of the remaining part of the Beirut port silos (if they can be reusable), the role played by the foundation and soil and if the silos' response would have changed if certain parameters were taken differently in the design. In this article, the damage and silos' displacement obtained from the numerical models were compared to the results obtained by the 3D laser scan. The results of this investigated article show that a blast magnitude of 337.5 tons TNT (938 tons of Ammonium Nitrate) best captures the silos' displacement and damage amount. The silos exhibit a tilt between 20 and $30 \mathrm{~cm}$ in the direction of the blast. The numerical results indicate that constructing the silos with higher compressive strength would not have affected the silos' damage. Nevertheless, adding the extra concrete coating and reinforcement layer in 2000 to the outer silos decreased the amount of damage in the silos. Moreover, reinforcing the ribs between the silos would have decreased the silos displacement and damage amount. Finally, the soil and the foundation played a positive role in the explosion by absorbing part of the released energy while the silos, in the current state, cannot be reused.

(C) 2021 MIM Research Group. All rights reserved.

\section{Introduction}

Serious damage to buildings and other infrastructures may be caused by accidental explosions, military explosions, and terrorist attacks [1 - 3]. In addition, failure of structures can occur due to faults in design such as the collapse of Terminal 2E Roissy at Charles de Gaulle airport in 2004 [4], due to large creep and shrinkage of concrete structures [5, 6], or it can be caused by earthquakes [7 - 9] and blast loading such as the 2020 Beirut port silos explosion.

On August 4, 2020, a large fire in warehouse number 12 started at the port of Beirut. The fire was followed by a huge explosion that sent a blast wave which radiated through the city. The explosion caused severe damage all over the city of Beirut and was heard as far away as Cyprus that is about $200 \mathrm{~km}$ across the Mediterranean Sea. This explosion left

\footnotetext{
*Corresponding author: sahar.ismail@net.usj.edu.lb

a orcid.org/0000-0003-2140-6969; b orcid.org/0000-0002-2960-8760; c orcid.org/0000-0001-5134-5496; DOI: http://dx.doi.org/10.17515/resm2021.286st0428
}

Res. Eng. Struct. Mat. Vol. 7 Iss. 4 (2021) 551-577 
more than 200 people were killed, and more than 7500 injuries. Moreover, it caused around $\$ 15$ billion damage in properties and left more than 300000 people homeless. The explosion, only few meters away from the Beirut port silos, created a crater approximately $140 \mathrm{~m}$ wide, which was then flooded with seawater as shown in Fig. 1. As a result, the blast wave caused extensive damage not only to the city of Beirut but also to the country's grains storage silos: the Beirut port silos (Fig. 2). The cause of explosion was blamed to the detonation of 2750 tons of Ammonium Nitrate that were stored at warehouse 12 in the port.

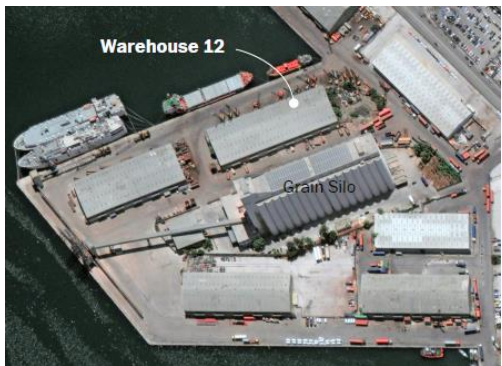

a)

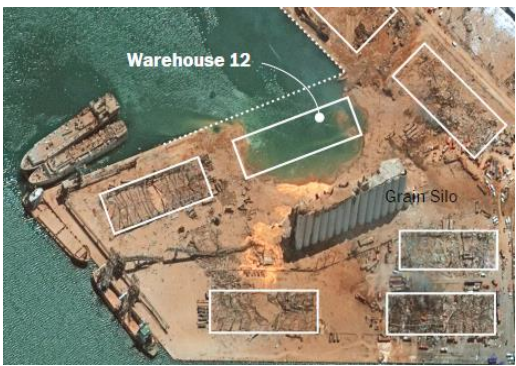

b)

Fig. 1 The Beirut port silos, a) before August 4, 2020 blast and b) after August 4, 2020 blast [10]
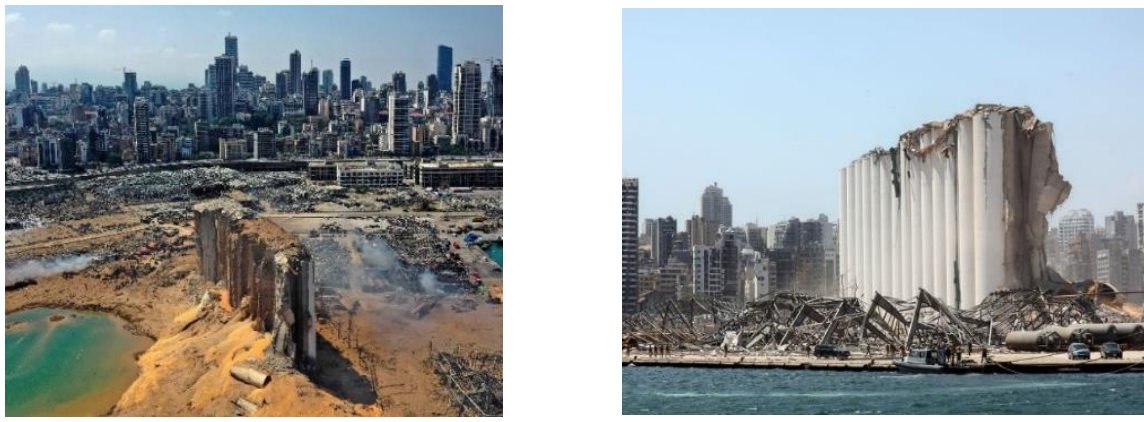

Fig. 2 The damaged grained Beirut port silos, after August 4, 2020 blast [11, 12]

Several blast incidents due to the explosion of Ammonium Nitrate occurred around the world (Table 1) such as in Texas, in the USA in 1947 that left 552 victims [13], in Toulouse, France in 2001 that left 20 victims [14], in Mihailesti Romania in 2004 that left 18 victims [15] and in West Texas, in the USA in 2013 that left 15 victims and more than 260 injuries [16]. As a result, even though Ammonium Nitrate is a common farm and garden fertilizer, it is a hazardous explosive chemical especially when it is contaminated (by intention) with fuel oil, diesel or triggered by a fire $[17,18]$. It should be noted that Ammonium Nitrate is listed in the European's Seveso Directive that regulates the storage and handling of all hazardous chemicals in Europe [19].

Bauer et al. [24] and King et al. [25] studied the degree of uncertainty associated with the explosive magnitude of Ammonium Nitrate. They found that an uncontaminated Ammonium Nitrate can be very difficult to detonate by any sort of flame, spark or friction under normal storage conditions. Ammonium Nitrate's detonation can only happen when its size is higher than the size of the critical charge and is characterized by a super-sonic pressure wave that travels through a material. Therefore, the initiation of an Ammonium 
Nitrate shock wave requires an enormous amount of energy [25]. Nevertheless, the Joint Research Center JRC [26] does not rule out the possibility of Ammonium Nitrate's decomposition under normal storage conditions.

Table 1. Main accidents worldwide caused by Ammonium Nitrate and the corresponding charges

\begin{tabular}{cccc}
\hline Blast incident location & Date & Casualties & $\begin{array}{c}\text { Ammonium } \\
\text { Nitrate (tons) }\end{array}$ \\
\hline Faversham, Kent, United Kingdom & April 2, 1916 & 115 deaths & 700 \\
[20] & September 21, 1921 & 561 deaths & 450 \\
Oppau, Germany [21] & April 16, 1947 & 552 deaths & $2086 \& 870$ \\
Texas, USA [13] & July 28, 1947 & 29 deaths & $1700-3309$ \\
Brest, France [20] & August 2, 1994 & 11 deaths & 80 \\
Porgera Gold Mine, Papua New & September 21, 2001 & 20 deaths & $200-300$ \\
Guinea [22] & May 24, 2004 & 18 deaths & 20 \\
Toulouse, France [14] & April 17, 2013 & 15 deaths & 240 \\
Mihailesti. Romania [15] & August 12, 2015 & 173 deaths & 800 \\
West Texas, USA [16] & August 4, 2020 & 204 deaths & \\
Port of Tianjian, China [23] & & & \\
Beirut port, Lebanon & &
\end{tabular}

In the work presented in this paper, the Beirut port silos blast on August 4, 2020 was analyzed using the 3D laser scan and 3D numerical model. The 3D laser scan was performed by the higher school of Engineering "ESIB" at Saint Joseph University of Beirut in collaboration with the Swiss company "Amann" Engineering. It estimated the amount of damage and deformation of the Beirut port silos. Due to its ability to provide important data, accelerating the workflow, avoiding expensive mistakes, and enhancing work productivity, 3D scan technique is being used in several industries such as engineering and medicine among others [27 - 29]. In this study, the 3D scan results were compared to the FE results, performed using Abaqus explicit. The 3D models allowed us to capture the response and damage of the silos in all its manifestations which provided a better understanding of the blast. Therefore, the objective of this paper is not only to check the Beirut port structural status following the blast, but also to explore and assess the effects and the contribution of several factors to the silos' damage amount. As such, after estimating the blast magnitude, this study examines if the remaining part of the Beirut silos can be reused. Also, it explores the role the soil and the foundation played in the blast and if the silos' response would have changed if certain parameters were taken differently in the design: silos' concrete strength, additional reinforcement and concrete coating added to the silos in 2000 and reinforcing the ribs between the silos.

\section{Description of the Analyzed Case Study}

\subsection{The Beirut Port Silos History}

In 1968, the Lebanese government at a cost of nearly $\$ 2.8$ million funded the construction of the Beirut port silos. This project was built by the Czech construction company "Prumstav" along with several Lebanese experts in the civil engineering domain. The Beirut port silos, as shown in Fig. 3, were constructed in three phases. In the first phase, in the late 1960s, 24 silos, formed of 3 rows of 8 silos each (in total 24 silos) were built. Then, in phase 2, also in the late 1960s, another 3 rows of 6 silos each (in total 18 silos) were built. Finally, in 1997, 6 extra silos were constructed to fulfill the country's grains reserves need. 
From 2000 to 2002, the $48 \mathrm{~m}$ height, $8.5 \mathrm{~m}$ diameter silos having a $17 \mathrm{~cm}$ wall thickness underwent restoration work due to concrete carbonation. In this work, the internal wall of the outer rows of the silos was increased by $12 \mathrm{~cm}$, i.e the wall thickness of these silos increased from 17 to $29 \mathrm{~cm}$. Therefore, just before the August 4, 2020 blast, the Beirut port silos were able to withhold 123200 tons of grains. The silos' capacity was divided into 48 big cells of 2000 tons each, as well as 26 smaller cells with 700 tons each and 30 cells with 300 tons each.

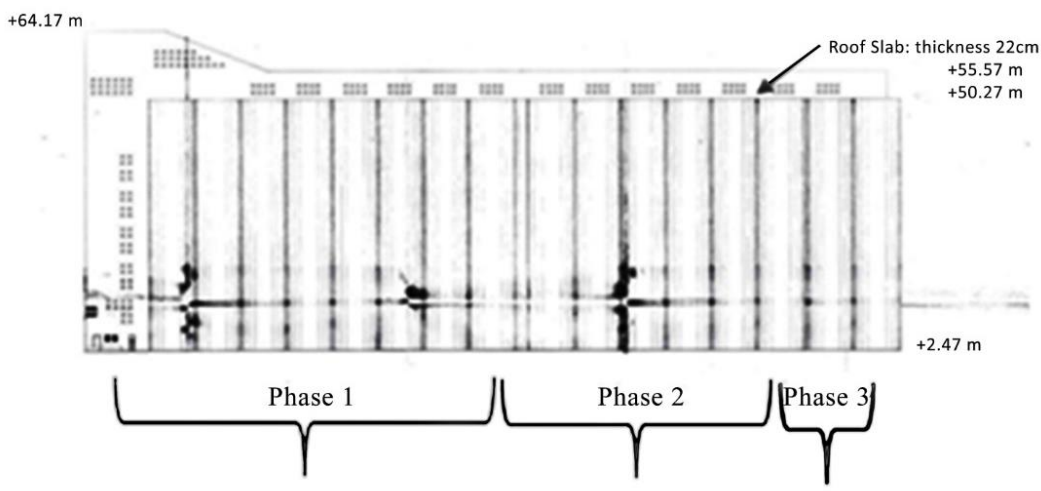

Fig. 3 The construction phases of the Beirut port silos

\subsection{The 3D Scan and the Equipment Used}

After the August 4, 2020 explosion, the Swiss Company "Amann" Engineering that is based in Geneva offered the Higher School of Engineering "ESIB" at the Saint Joseph University of Beirut free technical assistance to measure the damage in Beirut port silos using 3D scan. 3D scan technique creates high-precision 3D models of real objects by capturing several snapshots of an object and then merging them together. Thus, the 3D model, formed of small triangles or polygons that constitutes the mesh, replicates the object's geometry within minutes. This copy can be rotated and viewed from different angles. 3D scan technology has been gaining popularity in several industries such as in industrial design, engineering, medicine, forensics, archeology, heritage preservation, art and design, quality inspection, construction, automobile, etc.

After obtaining the permission from the investigation judge and the Lebanese army, the Saint Joseph University of Beirut and the Swiss team, escorted by the Lebanese army, performed the complex mission in two phases. During the first phase in September 2020, the Swiss equipment LEICA BLK360 imaging scanner (Leica geosystems) was used (Fig. 4(a)), while during the second phase in November 2020, the German equipment Z+F Imager 5010X scanner (Zoller \& Fröhlich) was used (Fig. 4(b)). The difference between the two equipment lies in the way they acquire the 3D points, the number of points captured per second and the correction of tilt measurements. The LEICA BLK360 allows the acquisition of 3D points with an integrated spherical imaging and a thermography panorama sensor system in up to 360000 points per second. It provides live image and scanner data stream viewing and editing with automatic tilt measurements. The $\mathrm{Z}+\mathrm{F}$ Imager comes with a special navigation system that estimates the scanner position and orientation to support the $\mathrm{Z}+\mathrm{F}$ Laser Control registration software during pre- and postregistration on-site. It includes a dynamic compensator that corrects angular tilts for each pixel during scan acquisition that has a rate of 1 million pixels per second. 


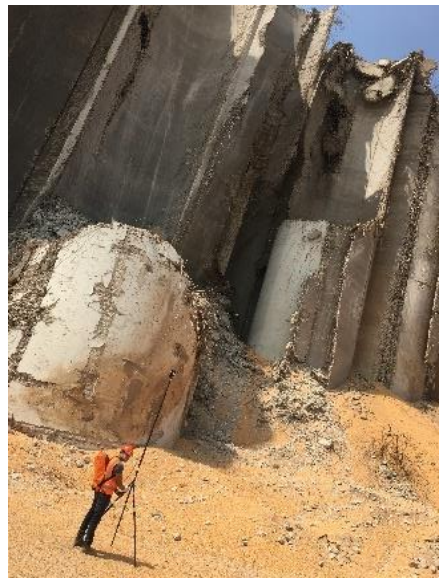

a)

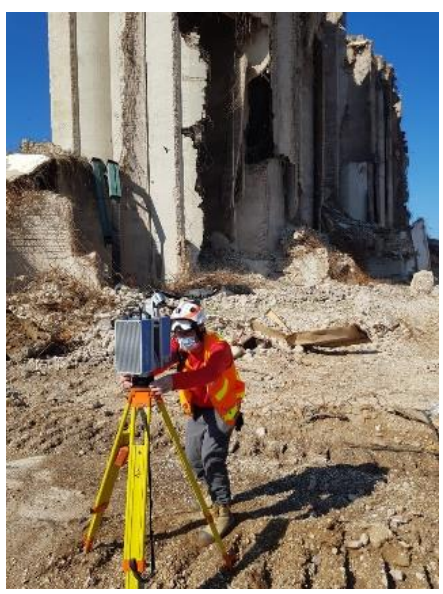

b)

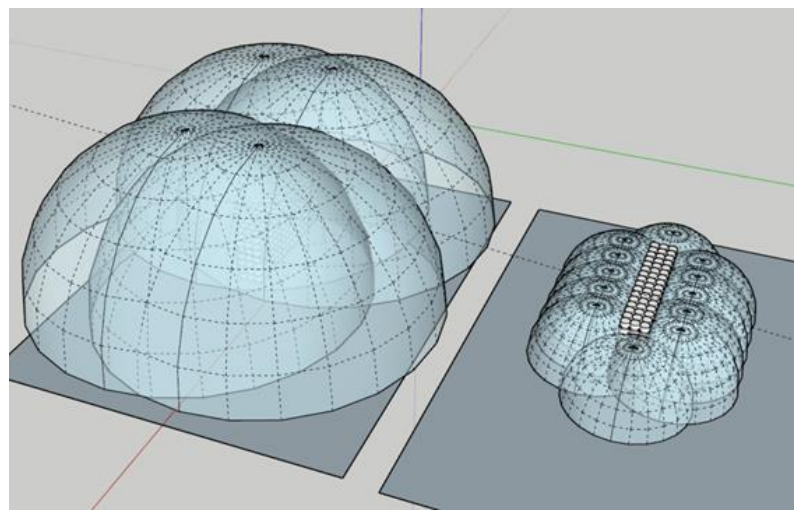

c)

Fig. 4 Scanning the Beirut port silos using a) LEICA BLK 360 and b) Z + F Imager 5010 $X$ Imaging scanner and c) Comparing the scope of silos' 3D scan (the left picture concerns the $\mathrm{Z}+\mathrm{F}$ scope and the right, the Leica scope)

Another difference is the scope range captured by each piece of equipment; i.e the panoramic and thermal camera. The LEICA BLK360 imaging scanner forced the team to stand far from the silos to capture the total silos' height and not be in danger. Whereas the $\mathrm{Z}+\mathrm{F}$ Imager 5010X allowed the team to sweep a volume 27 times larger per scan in a smaller amount of time since it has a larger scope range than the LEICA BLK360. The Z+F Imager is much more efficient in terms of color rendering as well as calibration between the laser device and the camera. Therefore, the use of the $\mathrm{Z}+\mathrm{F}$ Imager 5010X in the second phase allowed for a better final 3D scan result. Fig. 4(c) presents a comparison of the scope of the silos' 3D scan using the above equipment. The LEICA BLK360 completes full-dome scan, spherical and thermal 3D images with $6 \mathrm{~mm}$ at $10 \mathrm{~m}$ and $8 \mathrm{~mm}$ at $20 \mathrm{~m}$ point accuracy in less than 3 minutes using Waveform Digitizing (WFD) distance measurement system technology. In addition, the camera system is formed of a 15 Mpixel camera system, 150 Mpixel full-dome capture, HDR, LED flash Calibrated $360^{\circ} \mathrm{X} 300^{\circ}$ spherical image. While the thermal camera FLIR technology is based on a longwave infrared camera with thermal $360^{\circ} \mathrm{X} 70^{\circ}$ panoramic image. The $\mathrm{Z}+\mathrm{F}$ Imager $5010 \mathrm{X}$ scanner comes with an external 
thermal camera (Z+F T-Cam) that allows the application of infrared information to the scan. Thus, it generates $360^{\circ}$ full-dome thermal panorama scans in a fully automatic process. It records a full panorama (32 images) in 1:45 minutes with a resolution of $382 \mathrm{X}$ 288 pixel and an infrared spectrum of 7.5 to $13 \mu \mathrm{m}$ as well as a lens' field of view of $62^{\circ} \mathrm{X}$ $49^{\circ}$. As a result, the term thermo-panorama is scaled to a scan resolution of 2500 pixel at $360^{\circ}$ with a working range greater than $1.6 \mathrm{~m}$, a vertical field of view of $284^{\circ}$ and a horizontal field of view of $360^{\circ}$. Note that the LEICA BLK360, due to its small size, was used in the slopes of the silos while walking on the grains. On the other hand, although the $\mathrm{Z}+\mathrm{F}$ Imager $5010 \mathrm{X}$ provided more precise images, it was heavier and harder to manipulate than the LEICA BLK360 [30, 31].

As shown in Fig. 5, 752 million points of measure in three dimensions using 25 stations in $360^{\circ}$ panorama infrared images were obtained. Therefore, a full panoramic picture of the silos was acquired using the LEICA BLK360 as well as the Z+F Imager 5010X (Fig. 6 and 7 (the video)). The obtained results show that the silos exhibit a general tilt of 20 to $30 \mathrm{~cm}$ in the direction of the blast. It should be noted that this tilt is not related to the original silos' construction. The silos, in their current state, do not pass the silos' design codes. The damage in the silos can be explained as follows: either the inner part (inside half cylinder) is damaged and/or the pile head is deformed beyond the elastic range and therefore broken (Fig. 8).

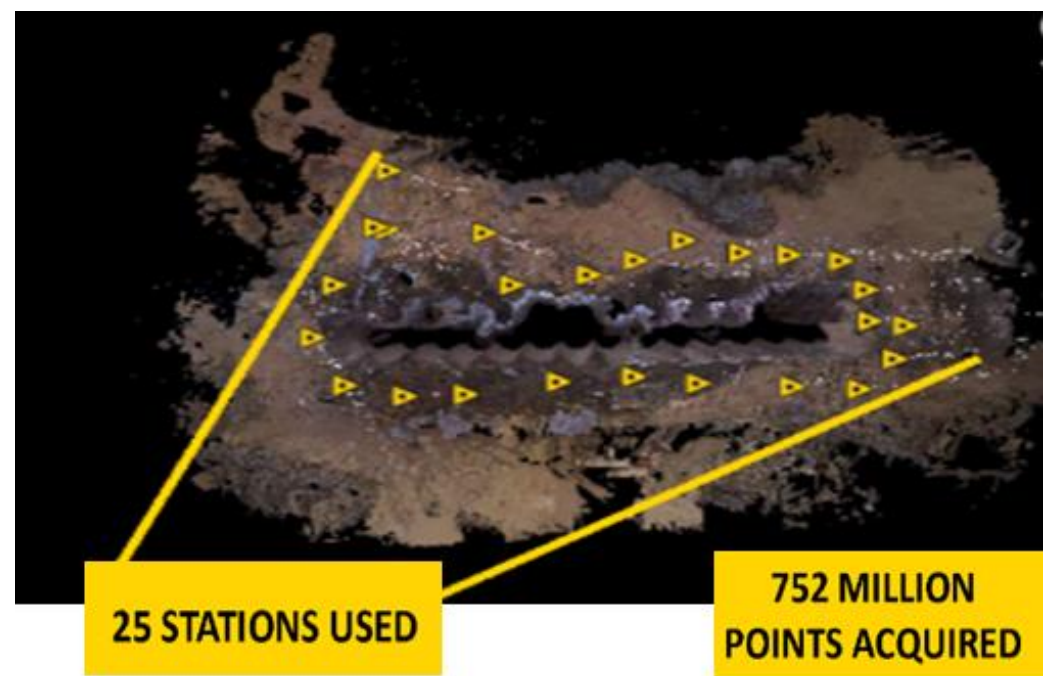

Fig. 5 The Beirut port silos 3D scan, points acquired, and stations used 

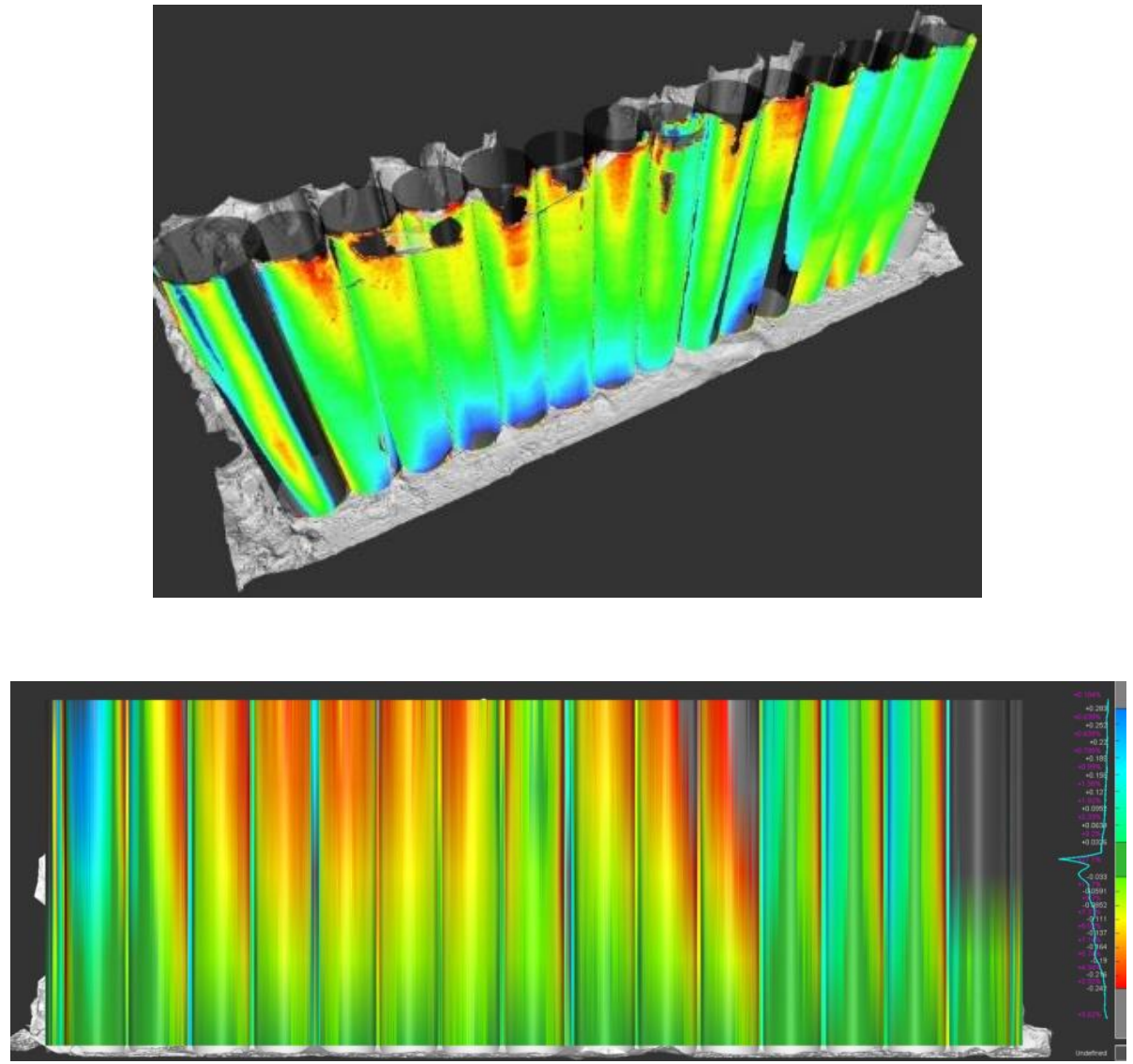

Fig. 6 The Beirut port silos 3D scan (the color shadings red, green and blue refer to a 20,10 and $0 \mathrm{~cm}$ displacement in the direction of the explosion)

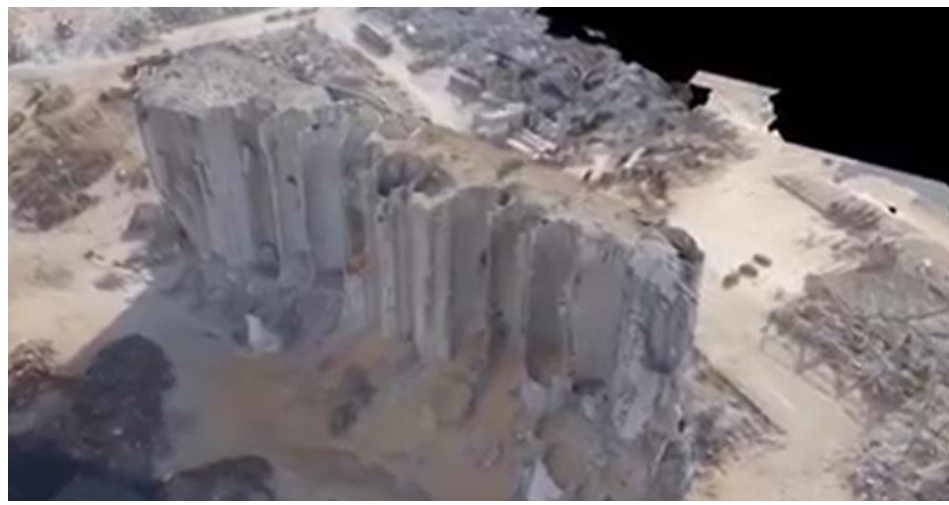

Fig. 7 The Beirut Port Silos 3D scan (open the link to access the video) 

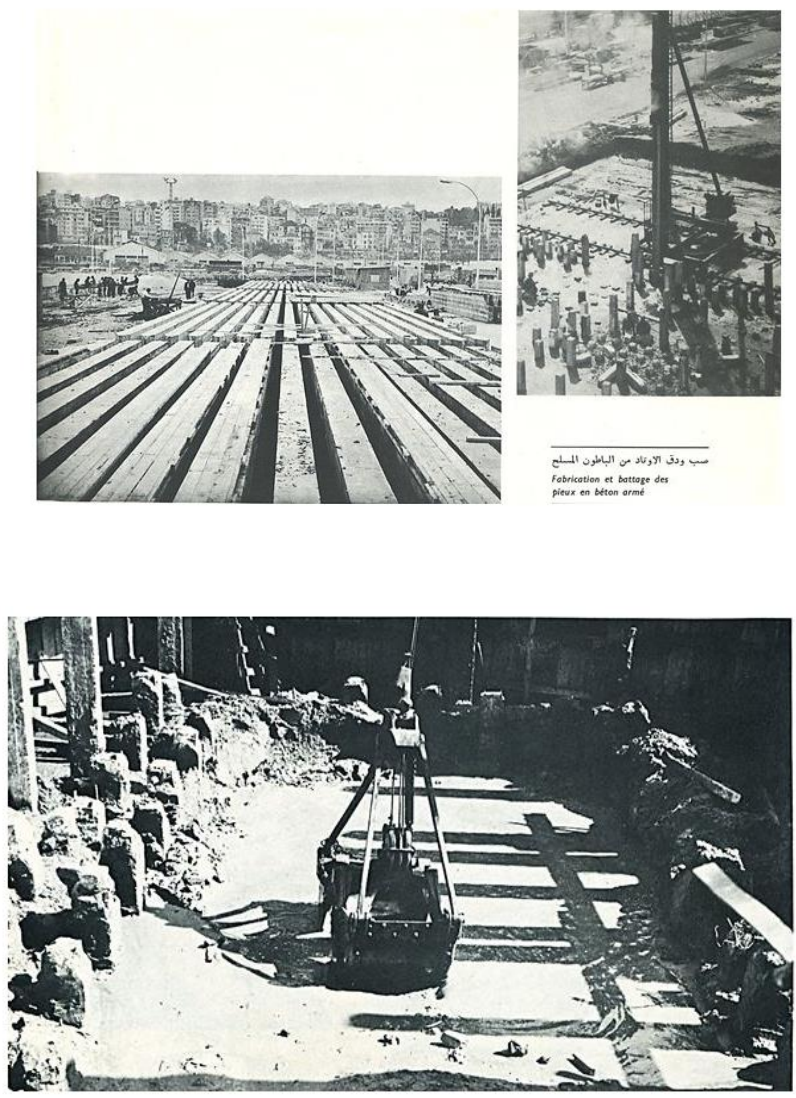

Fig. 8 Grain silos' foundation construction (pile cap and driven piles) and excavation for the base slabs as well exposing the piles head before casting the pile cap (GEER report [32])

\subsection{The Numerical Model}

3D Finite Element model was built to simulate the blast of the Beirut port silos using the FE software Abaqus explicit. The analyses were performed using large strain formulations while incorporating geometric nonlinearity. The simulated 3D models consisted of the reinforcement concrete silos and the grains (Fig. 9). The silos were built using 3137414 node doubly curved shell, reduced integration, hourglass control, finite membrane strains S4R shell elements, as detailed in Table 2. In addition, the silos steel reinforcement was defined as layers of reinforcement as part of the silos' shell elements using the rebars command (rebars' layers option) available in Abaqus. The grains: wheat and corn, available at the time of the explosion (Fig. 10) were built using 529678 8-node linear brick, reduced integration, hourglass control C3D8R solid elements (Table 2).

The $8.5 \mathrm{~m}$ diameter modeled reinforced concrete silos were $48 \mathrm{~m}$ in height. The restoration work performed in 2000 (concrete and steel reinforcement) were accounted for in the numerical model. Thus, the outer silos had a $29 \mathrm{~cm}$ wall thickness while the internal silos had a $17 \mathrm{~cm}$ wall thickness. Fig 11 presents the silos geometry and it details the steel reinforcement, adopted in the 1960s (Fig 11, b) and 2000s (Fig 11, c) designs. 

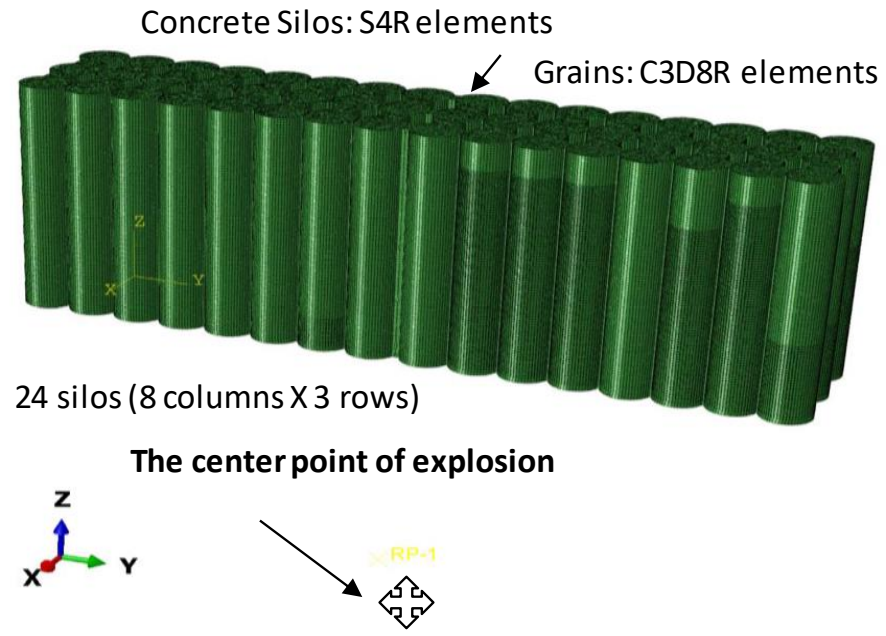

Fig. 9 The FE model

Table 2. Numerical model parts and properties

\begin{tabular}{|c|c|c|c|c|}
\hline Part & Material & Element type used & Number of nodes & $\begin{array}{l}\text { Number } \\
\text { of } \\
\text { elements }\end{array}$ \\
\hline Silos & $\begin{array}{c}\text { Reinforced } \\
\text { Concrete }\end{array}$ & S4R shell elements & 302071 & 313741 \\
\hline Grains & $\begin{array}{c}\text { Wheat and } \\
\text { Corn }\end{array}$ & C3D8R solid elements & 578970 & 529678 \\
\hline Pile cap & $\begin{array}{c}\text { Reinforced } \\
\text { Concrete }\end{array}$ & S4R shell elements & 4800 & 7902 \\
\hline Driven Piles & $\begin{array}{c}\text { Reinforced } \\
\text { Concrete }\end{array}$ & B31 beam elements & 20846 & 17868 \\
\hline Soil Medium & $\begin{array}{l}\text { Backfill } \\
\text { platform }\end{array}$ & C3D8R solid elements & 37500 & 30400 \\
\hline
\end{tabular}

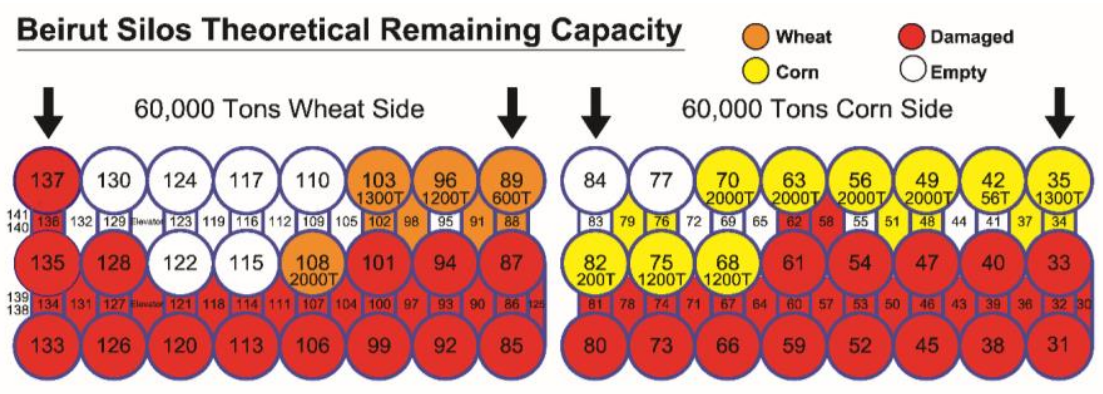

Fig. 10 Beirut silos grains capacity at the time of the blast 


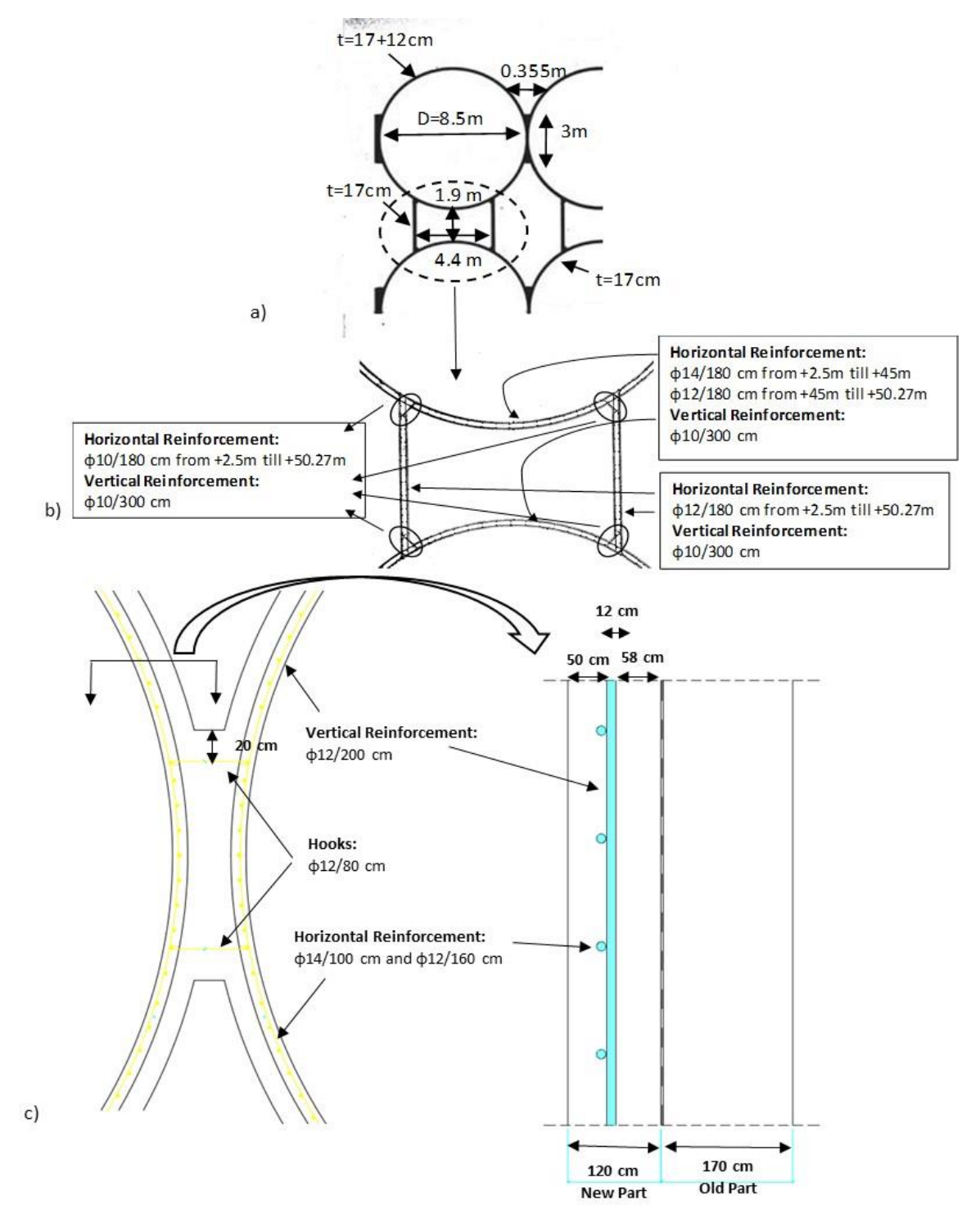

Fig. 11 a) The geometry of the Beirut port silos, b) The steel reinforcement of the Beirut port silos and c) The concrete and steel restoration work of the Beirut port silos

The blast on the silos was modeled using the CONWEP blast loading model in Abaqus explicit. This model simulates, through incident and reflected pressure, the loading effects caused by an explosion of an air blast (spherical waves) or a surface blast (hemispherical incident waves). Noting that the August 4, 2020 blast produced a hemispherical incident wave. The bottom of the silos' boundary was assumed to be fixed while the blast loading was applied at the silos' surface facing the explosion.

The relevant properties of the silos, steel and grains used in the models are presented in Table 3. In this Table, $\rho$ is the density $\left(\mathrm{kg} / \mathrm{m}^{3}\right), E$ is the Young modulus (GPa), $v$ is the 
Poisson's ratio, $\sigma_{y}$ is the yield stress (MPa), $\mathrm{K}$ is the ratio of the second stress invariant on the tensile meridian, $f b 0 / f_{c} 0$ is the ratio of initial equibiaxial compressive yield stress to initial uniaxial compressive yield stress, $c$ is the soil cohesion ( $\mathrm{kPa}), \Phi$ is the friction angle $\left({ }^{\circ}\right), \psi$ is the dilation angle $\left(^{\circ}\right)$ and $f_{c, m}^{\prime}$ is the mean concrete compressive strength (MPa). The simplified damage plasticity model was used to define the concrete in the silos [33]. In addition, the inelastic/plastic behavior of the steel reinforcement was simulated using elastic-perfectly plastic material behavior by defining the steel yield stress. Whereas the grains: wheat and corn, were assumed elastic based on EN1991-4 [34] provision. Noting that the grains were also simulated using plastic material. The results show that the permanent displacement at the head of the third row of silos slightly increases from elastic to plastic cases without affecting the amount of damage in the silos. For example, for the 337.5 tons TNT case, the permanent displacement at the head of the third row of silos only increases by $2.18 \%$ from elastic to plastic cases. Nevertheless, since the simulation running time of the plastic case needs twice as much as the elastic and the authors in this article wanted to account for the mass and movement of the grains, the grains were modeled using elastic properties.

Table 3. Materials Properties

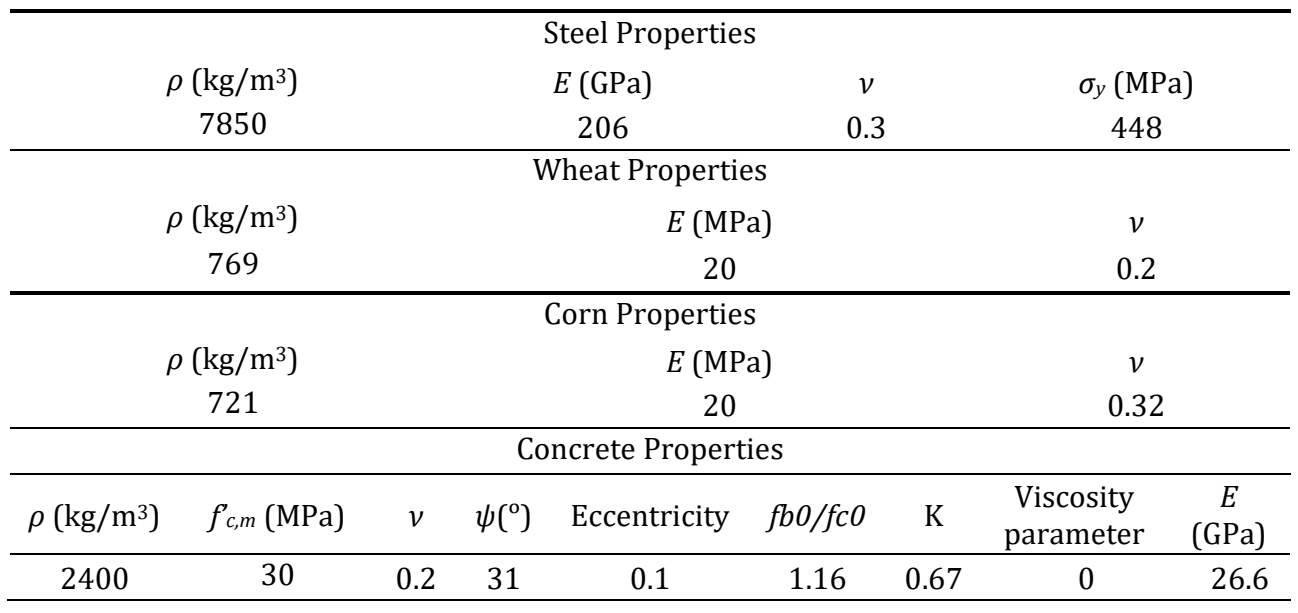

To determine the center point of explosion, i.e. the detonation center point, the aerial photos captured by the Lebanese Army forces as well as the investigation done by Forensic Architecture [35] were used. As shown in Fig. 12, the center point of explosion was located, at about $70 \mathrm{~m}$ in front of the silos and $40 \mathrm{~m}$ from the side of the silos, in warehouse number 12 which contained the explosive materials.

Since the CONWEP model in Abaqus requires the equivalent mass of explosive materials to be in terms of TNT, the mass of Ammonium Nitrate was transformed into an equivalent mass of TNT by multiplying it by a scaling factor. Note that most finite element software determines the effect of an explosion in terms of the TNT equivalency model [36]. Therefore, the consequence of an explosion is documented in TNT mass equivalent as follows:

$$
W_{T N T}=W_{\text {exp }} X P_{\text {exp }} X \eta
$$

where: $W_{T N T}$ is the equivalent mass of TNT,

$W_{\text {exp }}$ is the weight of the explosive substance, 
$P_{\text {exp }}$ is the explosive magnitude. It is defined by the ratio of the decomposition energy of 1 ton of substance (in J) divided by the detonation energy of 1 ton of TNT (J),

$\eta$ is the efficiency of the explosion. It is defined by the ratio of the real emitted to the theoretical energy of the explosion [37].

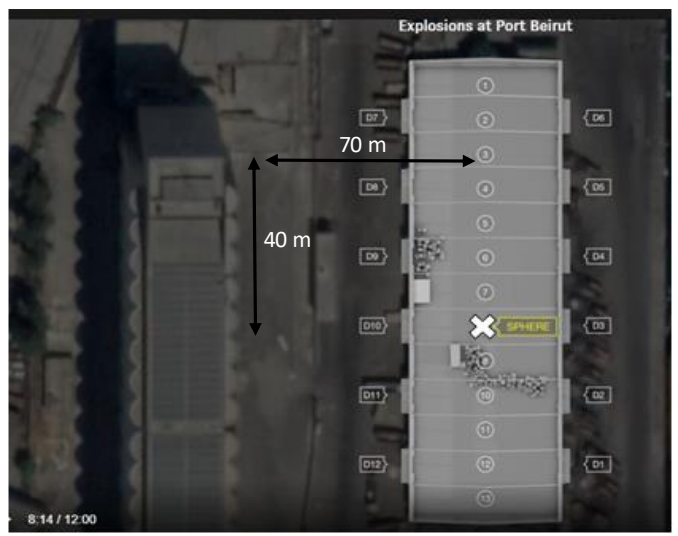

Fig. 12 The center point of explosion in warehouse number 12

Cooper [38] and Locking [39] among other researchers, showed that the TNT equivalency model might present a high degree of uncertainty in terms of explosive magnitude estimation. 20 to $30 \%$ errors may be found in TNT equivalency between different studies in the literature. This is related to the various tests adopted such as the "Air Blast" or the "Sand Crush" to determine the TNT equivalency and the conditions associated with these tests. As a result, HSE $[37,40]$ recommends not to accurately measure the explosive field since the explosion is not only related to the mass of explosive substance but also to the state of confinement, storage condition as well as the possibility of the presence of other contaminated materials that may affect the explosion and the amount of released energy. Nevertheless, several researchers in the literature estimated the equivalent mass of TNT by multiplying the quantity of the explosive substance by a scaling factor [14, 37, 41 - 44]. The value of this scaling factor $\left(P_{\exp } X \eta\right)$ varies from a study to another. In this study, a scaling factor of 0.39 was adopted which is based on Krauthammer [44] study and the Lebanese army investigation data. As such, the mass of Ammonium Nitrate used in the CONWEP model was transformed into an equivalent TNT mass by multiplying it by a scaling factor of 0.39 .

Finally, to make sure accurate and stable results are obtained in the FE simulations while minimizing the computational speed, a mesh sensitivity analysis was performed in Abaqus. Different meshing options were adopted for the shell silos and the solid grains: $0.25,0.5$ and $1 \mathrm{~m}$, to check the maximum amount of deformation in the least damaged row of silos (row number 3), occurring at the head. The results of the mesh sensitivity analysis, as shown in Fig. 13, indicate that at the head of the third row of silos, the maximum displacement varies on average 3.1 and $2.62 \%$ while the permanent displacement varies on average 3.19 and $4.43 \%$ between the 0.25 and $0.5 \mathrm{~m}$ and between the 0.5 and $1 \mathrm{~m}$ cases respectively. Since the computational time of the $0.25 \mathrm{~m}$ case is 45 hours while the computational time of the $0.5 \mathrm{~m}$ is 23 hours and the deformations at the head of the silos only varies by about $3 \%$ between the 0.25 and $0.5 \mathrm{~m}$, the $0.5 \mathrm{~m}$ mesh size was adopted in the FE analysis in this article. Also, to validate the FE model and to make sure the model is working correctly, first the artificial energy history was compared to the total energy. The results show that the artificial energy is significantly lower than the total internal energy. 
For example, for the 337.5 tons of TNT case, the maximum artificial energy equal to 66.18 MJ is lower than the maximum total internal energy equal to $1053.19 \mathrm{MJ}$, indicating that the results are trustworthy with small artificial effects. Then, the FE results were compared to the 3D scan results in terms of damage as well as deformations in the silos, as will be detailed in the next section.
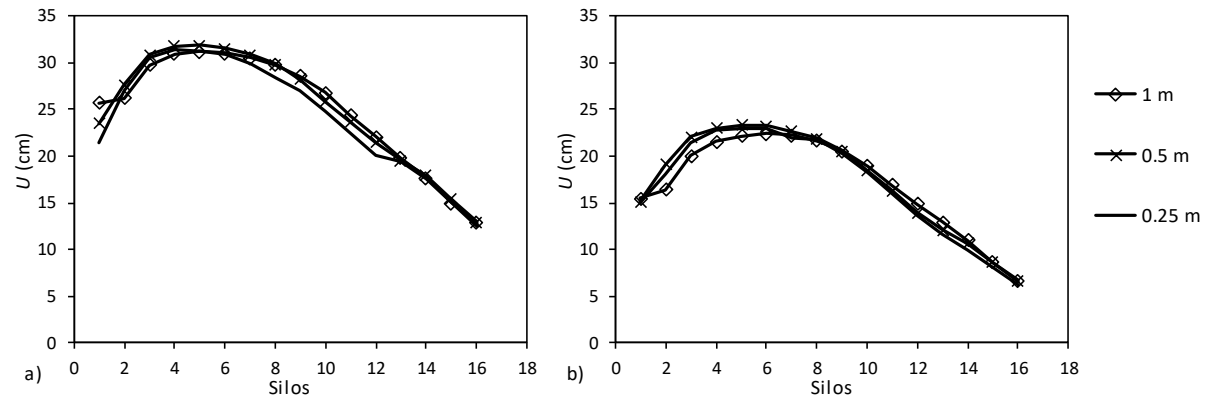

Fig. 13 a) Maximum displacement and b) permanent displacement in the direction of the blast at the head of the silos for different mesh sensitivity analysis

\section{Comparison Between Site Measurements and the Results of the Numerical Model}

To check the structural status of the remaining part of the Beirut port silos (if they can be reusable) and if the silos' response would have changed if certain parameters were taken differently in the design, an estimation of the blast magnitude was first performed. Thus, magnitudes of the blast, expressed in terms of equivalent masses of TNT, of 225, 337.5, 550, 875 and 1100 tons $(563,938,1375,2188$ and 2750 tons of Ammonium Nitrate) were considered/varied from the baseline case. The baseline case accounts for a mean concrete compressive strength of $30 \mathrm{MPa}$ with all additional concrete coating and steel reinforcement added in 2000 and includes all grains available at the time of the explosion, as described in section 2. Moreover, the blast loading was applied at the silos' surface facing the explosion with the detonation center point as indicated in Fig. 12 in the warehouse which contained the explosive materials. The displacements in the direction of the explosion at the head of the silos in the third row, shown in Fig 14, clearly demonstrate the significant contribution of the magnitude of the blast. It should be noted that a maximum and a permanent displacement were obtained for each silo. Since a permanent displacement was exceeded, then yield strength was exceeded. Note that the third-row silos' numbering in is indicated in Fig. 15.

For example, in silo 4, as shown in Fig. 14 and 16 and Table 4, the maximum displacement increases from 21.3 to $45.4 \mathrm{~cm}$ while the permanent displacement increases from 14.2 to $37.6 \mathrm{~cm}$ as the blast magnitude is increased from 225 to 1100 tons TNT. Based on the above, the FE results were henceforth compared to the 3D scan results. Fig. 16 compares the displacement of the silos in the direction of the blast based on the 3D scan and the FE result. The results show that the first silo in the third row (the least damaged row), has lost its geometry. Whereas the other silos in this row have pertained their geometry and their $8.5 \mathrm{~m}$ diameter; nevertheless, they tilted around $20 \mathrm{~cm}$. Therefore, the silos in their current state, do not pass the limits set by design codes such as Eurocode [45]. The results of the 3D scan, presented in Fig. 6, points out to a displacement of $20 \mathrm{~cm}$ (in red), $10 \mathrm{~cm}$ (in green) and $0 \mathrm{~cm}$ (in blue) in the direction of the explosion. 

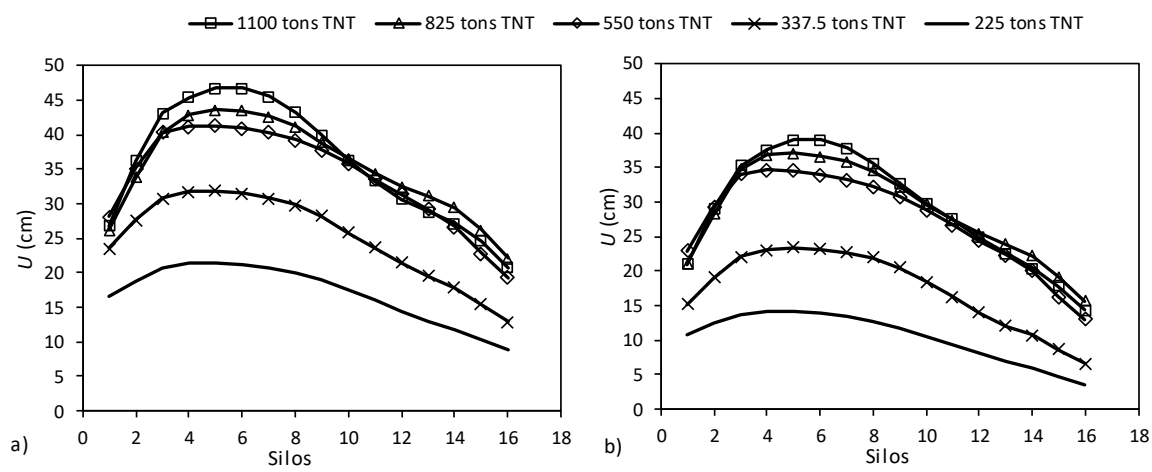

Fig. 14 a) Maximum displacement and b) permanent displacement in the direction of the blast at the head of the silos for different blast magnitudes (baseline case)

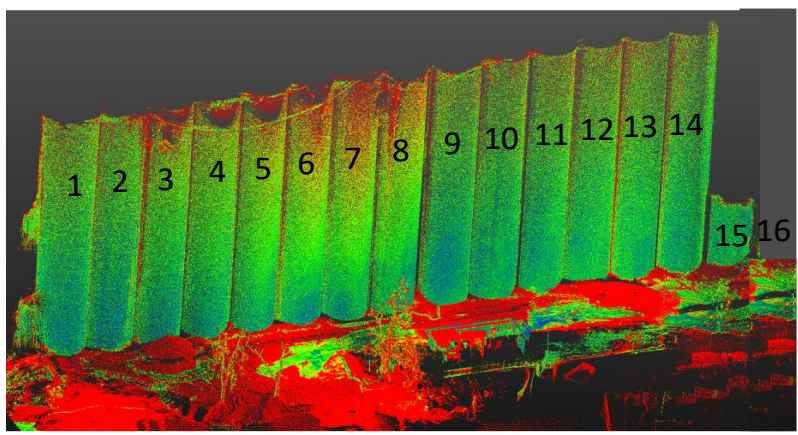

Fig. 15 Silos 1 to 16 in the third row

Comparing the results of Fig. 6 (3D scan) to Fig. 14 and 17 (FE results), we obtain that blast magnitudes of 550, 875 and 1100 tons TNT do not compare favorably to the results obtained from the 3D scan. A blast magnitude of 337.5 tons TNT (938 tons of Ammonium Nitrate) is found to best capture the 3D scan results and therefore, the real silos' displacement and damage. This is clearly illustrated in Tables 4 and 5 and Fig. 6 where silos 2 to 10 present a permanent displacement of around $20 \mathrm{~cm}$ while silos 11 to 14 present a permanent displacement of around $10 \mathrm{~cm}$. For example, for silos 4, 5 and 9, the difference between the $\mathrm{FE}$ and 3D scan results is equal to 22,14 and $3 \%$ for the estimated 337.5 tons TNT case while it is equal 52, 49 and $39 \%$ for the 1100 tons TNT case. It should be noted that Rigby et al. [46], using empirical formula estimated the magnitude of the blast to an equivalent mass between 550 to 1100 tons TNT. In addition, Diaz [47] using images and videos' recordings of the explosion posted on social media, estimated the magnitude of the blast to be in the order of 1100 tons TNT while Aouad et al. [48] using fireball analysis, estimated the magnitude of the blast to be equivalent to 810 tons TNT. Also, Stennett et al. [49] and Pasman et al. [50] using videos posted on social media in addition to analyzing 


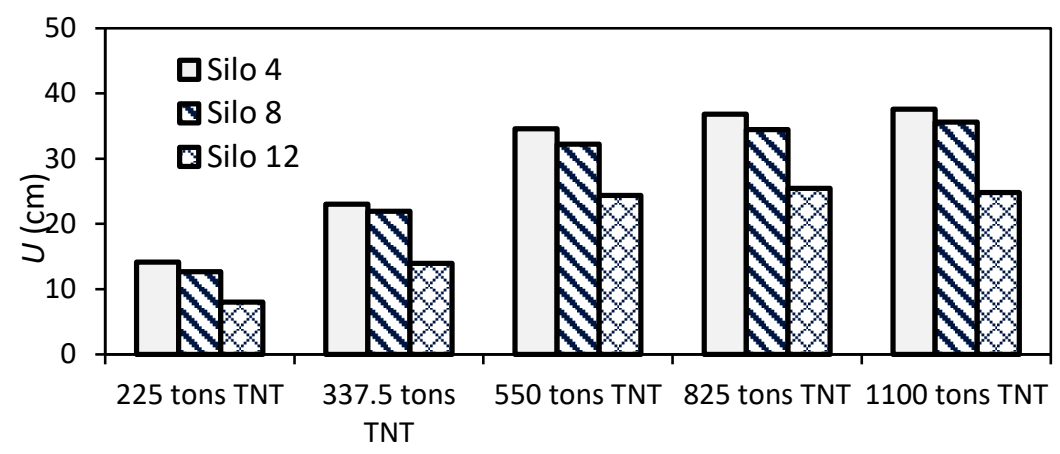

Fig. 16 Maximum permanent displacement in silos 4, 8 and 12 for the different blast magnitudes
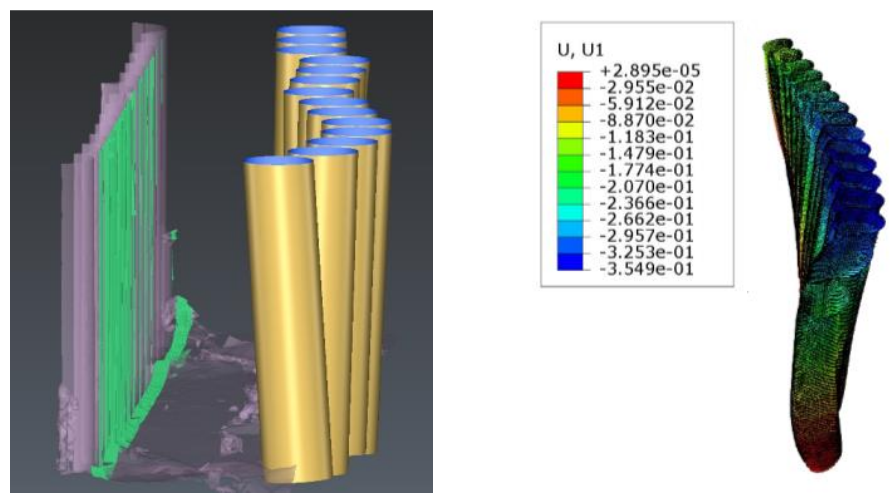

Fig. 17 Displacement of the silos in the direction of the blast a) 3D scan and b) FE results (in $\mathrm{m}$ )

the crater formed by the blast [50] estimated the blast magnitude to an equivalent 637 tons of TNT with lower and upper bounds of 407 and 1000 tons and 650 tons of TNT with lower and upper bounds of 300 and 1000 tons respectively. Also, Valsamos et al. [51], based on the geospatial data taken from the open-source world map OpenStreetMap, estimated the blast magnitude to an equivalent 1100 tons TNT. To present the state of damage of the 337 tons TNT estimated case, the silos' damages in compression and tension are presented in Fig 18. The amount of silos' damage, extracted from the FE models, presents the degradation of the silos' elastic stiffness and is described by the compressive damage variable " $\mathrm{d}_{\mathrm{c}}$ " (damage in compression) and the tensile damage variable " $\mathrm{d}_{\mathrm{t}}$ " (damage in tension), where these damage variables range from 0 : no damage to 1 : destruction. Moreover, to show the state of damage of the silos' elements, the cumulative surface damage rate curves are plotted in Fig. 19. On the ordinate is the percentage of the damaged surface having undergone the amount of damage indicated while on the abscissa is the damage indicator (1 refers to completely damaged elements/surfaces). Finally, the status of damage of the 1100 and 337.5 tons of TNT are shown in Fig 20. As indicated by these figures, for the 1100 tons TNT case, the first and second row of silos are destroyed. On the other hand, for the 337.5 tons of TT case, the first row of silos is destroyed while the second is partially destroyed, similar to reality where part of the second row of silos is still visible after the explosion (Fig 2). 
Table 4. Permanent displacement in the direction of the blast $(\mathrm{cm})$ - FE results

\begin{tabular}{cccccccc}
\hline FE/different blast magnitudes & 1 & 2 & 3 & 4 & 5 & 6 & 7 \\
\hline 225 tons TNT & 10.87 & 12.40 & 13.78 & 14.18 & 14.21 & 13.91 & 13.31 \\
337.5 tons TNT & 15.15 & 19.07 & 22.03 & 23.03 & 23.35 & 23.22 & 22.69 \\
550 tons TNT & 22.94 & 29.31 & 33.99 & 34.63 & 34.50 & 33.96 & 33.22 \\
825 tons TNT & 21.08 & 28.22 & 34.75 & 36.86 & 37.01 & 36.63 & 35.82 \\
1100 tons TNT & 21.02 & 29.02 & 35.21 & 37.59 & 38.95 & 38.94 & 37.79 \\
\hline
\end{tabular}

Table 4 (con.). Permanent displacement in the direction of the blast (cm)- FE results

\begin{tabular}{cccccccccc}
\hline FE/different blast magnitudes & 8 & 9 & 10 & 11 & 12 & 13 & 14 & 15 & 16 \\
\hline 225 tons TNT & 12.65 & 11.72 & 10.48 & 9.26 & 8.02 & 6.92 & 6.02 & 4.84 & 3.56 \\
337.5 tons TNT & 21.92 & 20.55 & 18.44 & 16.30 & 13.99 & 12.10 & 10.68 & 8.66 & 6.57 \\
550 tons TNT & 32.21 & 30.82 & 28.85 & 26.63 & 24.41 & 22.36 & 19.97 & 16.24 & 13.04 \\
825 tons TNT & 34.47 & 32.25 & 29.72 & 27.40 & 25.43 & 23.93 & 22.17 & 19.18 & 15.67 \\
1100 tons TNT & 35.62 & 32.66 & 29.83 & 27.49 & 24.83 & 22.53 & 20.35 & 17.86 & 14.39 \\
\hline
\end{tabular}

Table 5. Comparison between the FE and 3D scan results

\begin{tabular}{cccccccc}
\hline & \multirow{2}{*}{ silo } & \multicolumn{7}{c}{ FE (tons TNT) } & \multirow{2}{*}{ 3D scan } \\
\cline { 3 - 7 } & & $225 \mathrm{kt}$ & 337.5 & $550 \mathrm{t}$ & 825 & 1100 & \\
\hline$U(\mathrm{~cm})$ & 4 & 14.2 & 23.0 & 34.6 & 36.9 & 37.6 & 18 \\
\% difference (3D scan to FE) & & -27.0 & 21.8 & 48.0 & 51.2 & 52.1 & - \\
$U(\mathrm{~cm})$ & & 14.2 & 23.3 & 34.5 & 37.0 & 39.0 & 20 \\
\% difference (3D scan to FE) & 5 & -40.7 & 14.3 & 42.0 & 46.0 & 48.7 & - \\
$U(\mathrm{~cm})$ & & 11.7 & 20.6 & 30.8 & 32.2 & 32.7 & 20 \\
\% difference (3D scan to FE) & 9 & -70.7 & 2.7 & 35.1 & 38.0 & 38.8 & - \\
\hline
\end{tabular}

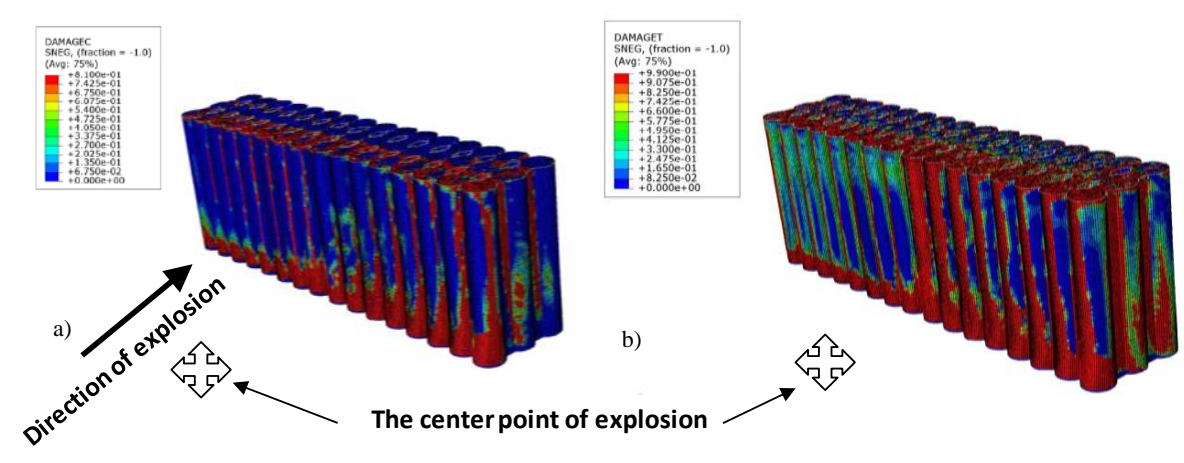

Fig. 18 Damage in a) compression and b) tension- 337.5 tons TNT baseline case (FE) (Damage variables range from 0 (no damage) to 1 (destruction)) 


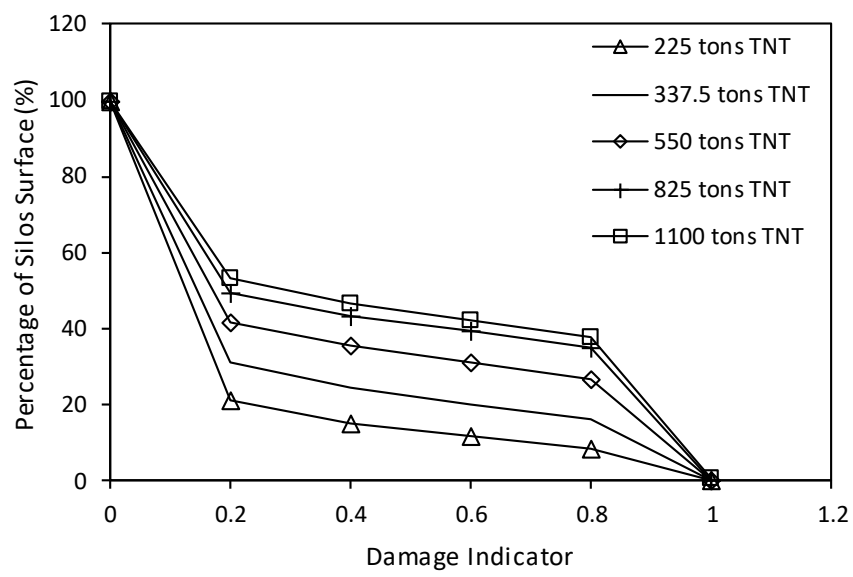

Fig. 19 The cumulative surface damage rate curve

a)

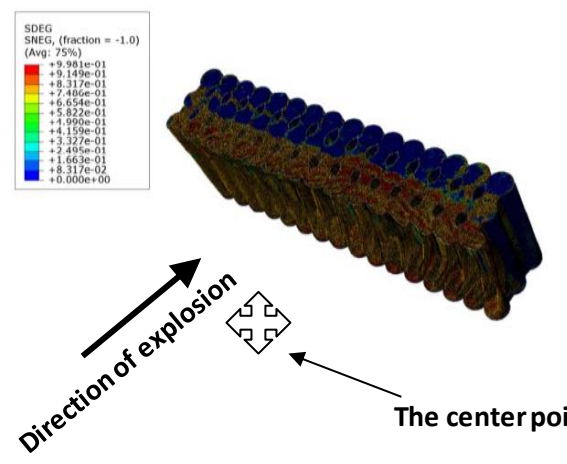

b)
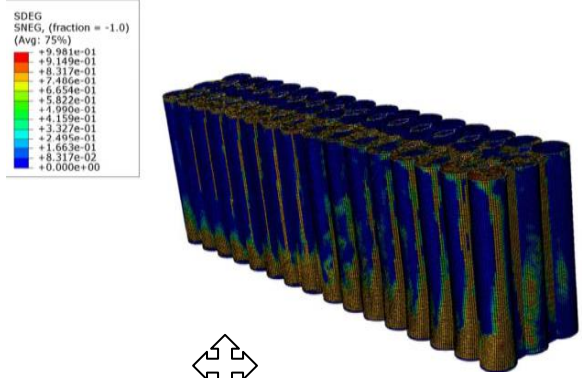

Fig. 20 The SDEG output of the a) 1100 and b) 337.5 tons of TNT simulated cases

(Damage variables range from 0 (no damage) to 1 (destruction))

\section{Analysis of Additional Parameters Responses to the Blast Loading}

\subsection{Effect of the Concrete Strength}

To study the effect of concrete strength, the displacement response of Beirut port silos was investigated for concrete compressive strengths $f_{c, m}^{\prime}$ : 30 and $40 \mathrm{MPa}$ starting from the baseline scenario. The results obtained and presented in Fig. 14, 21 and 22 indicate that for low levels of blast magnitude (225 tons and 337.5 tons TNT), $f_{c, m}^{\prime}$ does not affect the silos' displacement. The average ratio of permanent displacement at the head of the silos for the case of $f_{c, m}^{\prime}=40 \mathrm{MPa}$ to $f_{c, m}^{\prime}:=30 \mathrm{MPa}$ in the direction of the explosion is around 1.00 and 1.03 for 225 tons and 337.5 tons TNT respectively. However, as the magnitude of the blast increases from 550 tons to 1100 tons TNT, this ratio increases from 1.09 to 1.36 for the case of $f_{c, m}^{\prime}=40 \mathrm{MPa}$ to $f_{c, m}^{\prime}:=30 \mathrm{MPa}$. 


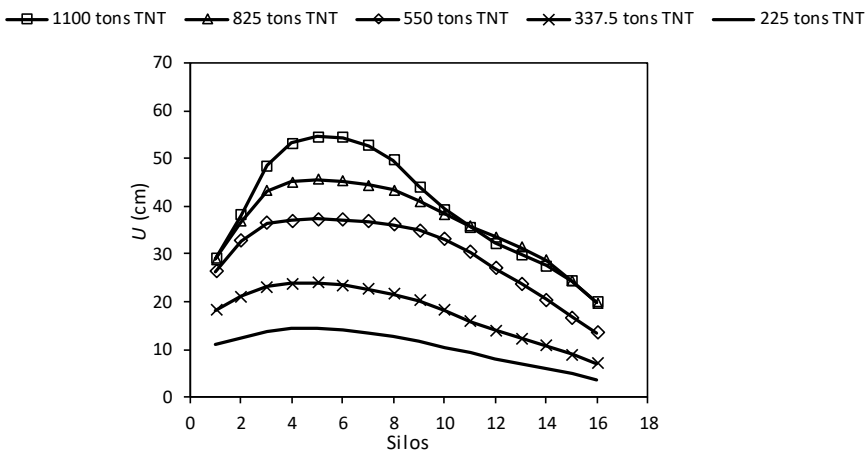

Fig. 21 Permanent displacement in the direction of the blast at the head of the silos for different blast magnitudes in the case of $f_{c, m}^{\prime}=40 \mathrm{MPa}$

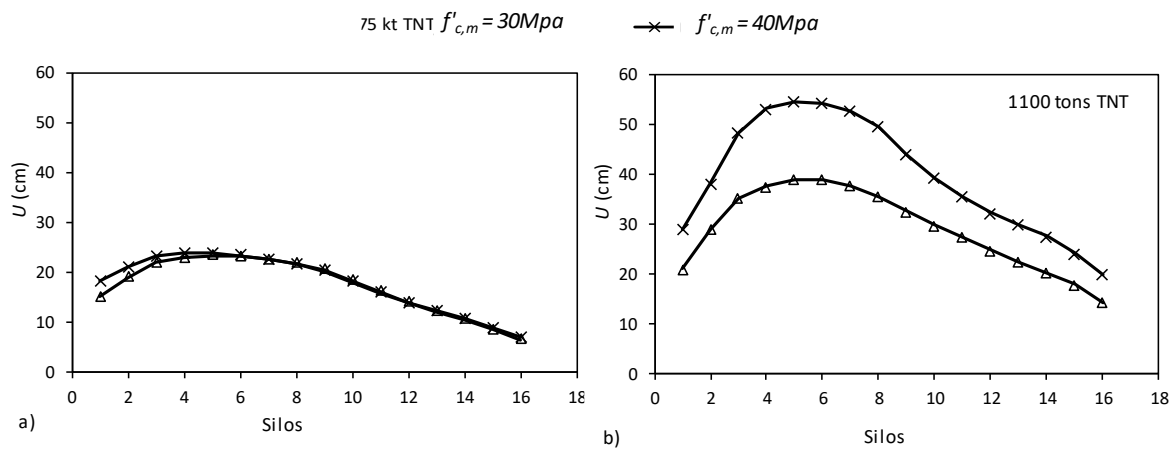

Fig. 22 Permanent displacement in the direction of the blast at the head of the silos for different concrete strength for a blast magnitude of a) 337.5 tons TNT and b) 1100 tons TNT

The significant contribution of concrete compressive strength as the magnitude of the blast increases may be due to the improvement of concrete shear resistance that leads to a reduction in the absorbing capacity of the blast energy. In general, the concrete shear strength increases with the increase in compressive strength. In addition, concrete with higher compressive strengths has greater resistance to blast loading [52]. Therefore, as the compressive strength increases, the concrete becomes stronger and able to withstand more load; in other words, it can withstand more permanent deformation. Noting that the increase in concrete compressive strength makes the latter more ductile, causing the failure of the structure in a brittle manner. This is manifested by the decrease not only in the amount of energies stored in the model under the blast model (the strain energies) but also in a decrease in the total and kinetic energies. For example, as the concrete compressive strength increases from 30 to $40 \mathrm{MPa}$ for the 1100 tons cases, the strain energy decreases from 480.29 to $395.50 \mathrm{MJ}$ and the total energy decreases from 29.60 to 26.14 MJ. The increase in concrete compressive strength also causes a decrease in the amount/level of silos' damage. Nevertheless, for the low level 337.5 tons of TNT estimated blast magnitude, designing silos with higher compressive strength would not have affected the damage obtained in Beirut port silos. 


\subsection{Effect of the Additional Reinforcement and Concrete Coating (ARC) Added in 2000}

To assess the contribution of the additional reinforcement and concrete coating (ARC), added from 2000 to 2002 to the outer silos, the damage and displacement behavior of the silos in the case of "no ARC" was compared to the case of "with ARC" (baseline case) for the different blast magnitudes. In the restoration work, the internal wall of the outer rows of the silos was increased by $12 \mathrm{~cm}$ and an extra layer of steel reinforcement was added as shown in Fig. 11. The results, presented in Fig. 23 and Table 6, show that the silos with "no ARC" exhibit lower tilting/displacement but a higher amount of damage (in compression and tension) for blast magnitudes greater than 337.5 tons TNT compared to the "with ARC" cases. For example, the ratio of permanent displacement in the direction of the blast for the case "with ARC" compared to the "no ARC" case in silo number 1 is equal to 0.75 for 225 tons TNT, while it is equal to 0.97 and 1.09 for 337.5 tons TNT and 882.5 tons TNT respectively. Similarly, this ratio in silo number 6 is equal to 0.82 for 225 tons TNT, while it is equal to 1.25 and 1.35 for 337.5 tons TNT and 882.5 tons TNT respectively. Therefore, for the estimated blast magnitude 337.5 tons TNT, the case "with ARC" (baseline case) exhibits on average a $5 \%$ greater amount of displacement compared to the "no ARC" case. It should be noted that silos 15 and 16 were destroyed in the blast. For the estimated blast case (337.5 tons TNT), the amount of damage in compression and tension exhibited in the silos is greater in the case of "no ARC" (Fig. 24) compared to the "with ARC" case (Fig. 18). As a result, the FE results indicate that reinforcing the outer silos from 2000 to 2002 played a positive role in the blast by decreasing the amount of the silos' damage.

Table 6. Ratio of permanent displacement in the direction of the blast $(\mathrm{cm})$ of the cases with ARC to no ARC

\begin{tabular}{ccccccccc}
\hline $\begin{array}{c}\text { Additional } \\
\text { reinforcement }\end{array}$ & $\begin{array}{c}\text { Magnitude of the } \\
\text { blast (tons TNT) }\end{array}$ & 1 & 2 & 3 & 4 & 5 & 6 & 7 \\
\hline & 225 & 0.75 & 0.77 & 0.82 & 0.84 & 0.84 & 0.82 & 0.80 \\
disp (with ARC)/ disp & 337.5 & 0.97 & 1.06 & 1.19 & 1.22 & 1.24 & 1.25 & 1.24 \\
(no ARC) & 550 & 1.52 & 1.66 & 1.75 & 1.68 & 1.61 & 1.60 & 1.61 \\
& 825 & 1.09 & 1.18 & 1.35 & 1.37 & 1.35 & 1.35 & 1.36 \\
& 1100 & 0.98 & 1.08 & 1.20 & 1.22 & 1.24 & 1.25 & 1.23 \\
\hline
\end{tabular}

Table 6 (con.). Ratio of permanent displacement in the direction of the blast (cm) of the cases with ARC to no ARC

\begin{tabular}{ccccccccccc}
\hline $\begin{array}{c}\text { Additional } \\
\text { reinforcement }\end{array}$ & $\begin{array}{c}\text { Magnitude of } \\
\text { the blast (tons } \\
\text { TNT) }\end{array}$ & 8 & 9 & 10 & 11 & 12 & 13 & 14 & 15 & 16 \\
\hline & 225 & 0.77 & 0.73 & 0.68 & 0.64 & 0.61 & 0.59 & 0.56 & 0.49 & 0.40 \\
disp (with ARC)/ & 337.5 & 1.23 & 1.20 & 1.13 & 1.04 & 0.94 & 0.85 & 0.79 & 0.69 & 0.58 \\
$\operatorname{disp}($ no ARC) & 550 & 1.64 & 1.70 & 1.74 & 1.73 & 1.75 & 1.73 & 1.62 & 1.41 & 1.24 \\
& 825 & 1.37 & 1.41 & 1.43 & 1.42 & 1.46 & 1.49 & 1.56 & 1.53 & 1.33 \\
& 1100 & 1.20 & 1.18 & 1.17 & 1.17 & 1.15 & 1.14 & 1.12 & 1.08 & 0.97 \\
\hline
\end{tabular}



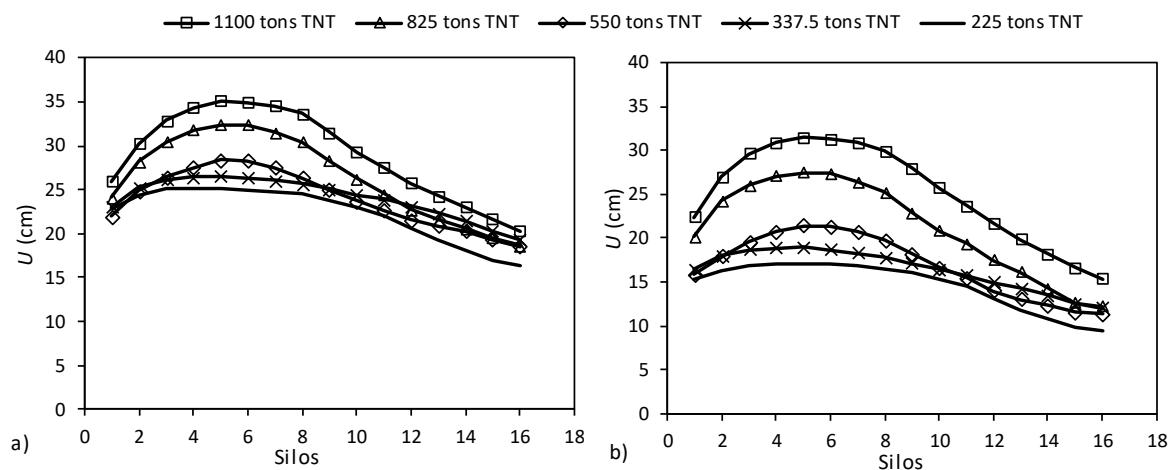

Fig. 23 a) Maximum displacement and b) permanent displacement in the direction of the blast at the head of the silos for different blast magnitudes in the case of no ARC

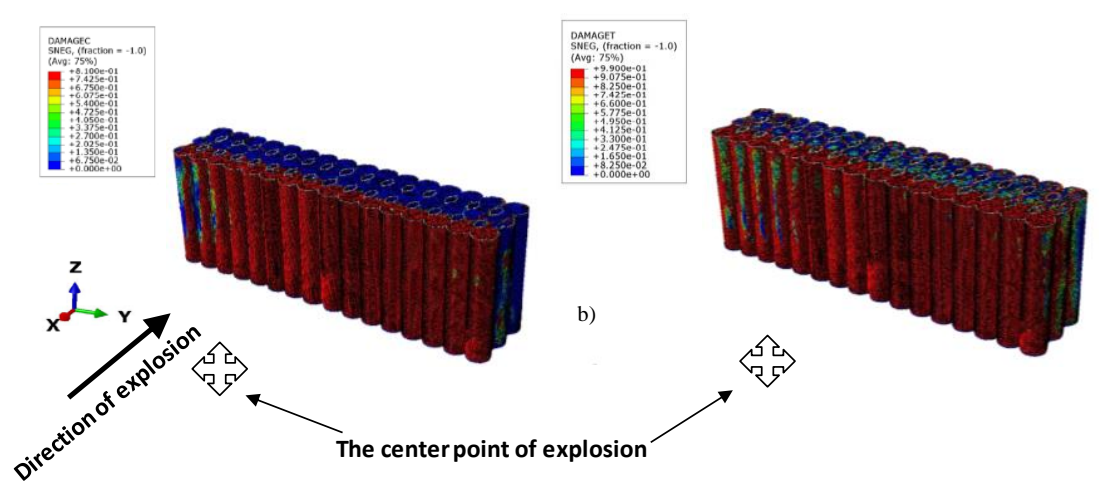

Fig. 24 Damage in a) compression and b) tension 337.5 tons TNT with no ARC (FE)

\subsection{Effect of Reinforcing the Ribs Between the Silos}

To check if reinforcing the ribs between the silos, such as the ARC performed from 2000 to 2002, would have decreased the damage of Beirut port silos, the estimated blast magnitude 337.5 tons of TNT case was simulated for the case without and with additional reinforcement in the ribs. The numerical results, presented in Fig. 25 and 26, show that if the ribs were reinforced, they would have played a significant role in the blast by decreasing the silos displacement as well as damage amount. At the head of the silos and in the direction of the explosion, the maximum and permanent displacements decrease on average by $12 \%$ and $20 \%$, respectively for the case with to without additional reinforcement in the ribs. For example, in silos 4 and 5 , that exhibit the maximum displacement and damage amount in the direction of the explosion, the permanent displacement decreases from 23.02 and $23.35 \mathrm{~cm}$ to 20.60 and $20.49 \mathrm{~cm}$ when reinforcing the ribs. As a result, the FE results indicate that reinforcing the ribs would have not only decreased the silos' displacement, but it would have played a positive role in the explosion by absorbing a small part of the released energy. The strain energy (the energy stored in the model under the blast loading), the dissipated energy (the wasted energy outside the model) and the total energy (the sum of all potential energies in the system) released from 
the models are 3, 5\% and 4\% lower in the case when additional reinforcements were added to the ribs.
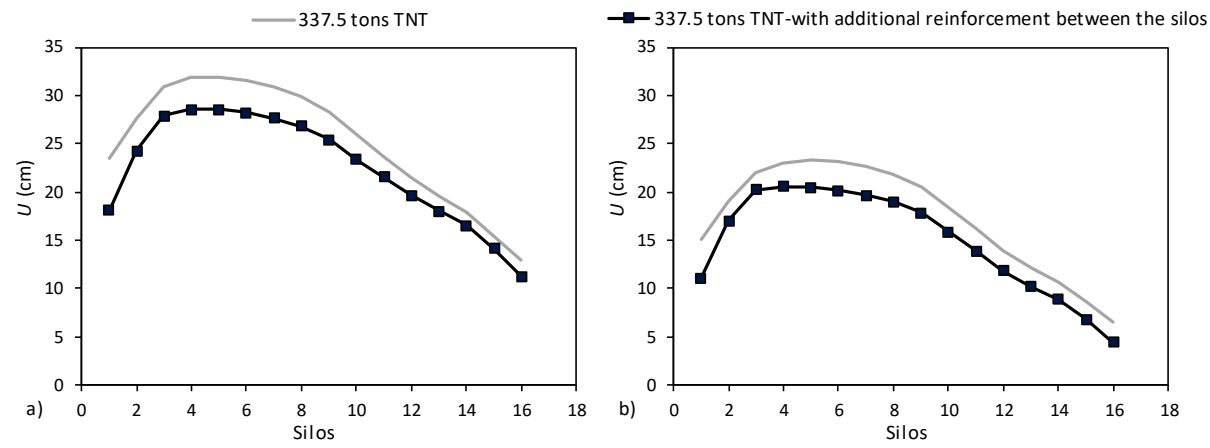

Fig. 25 a) Maximum and b) Permanent displacement in the direction of the blast for the 337.5 tons TNT without and with additional reinforcement in the ribs between the silos
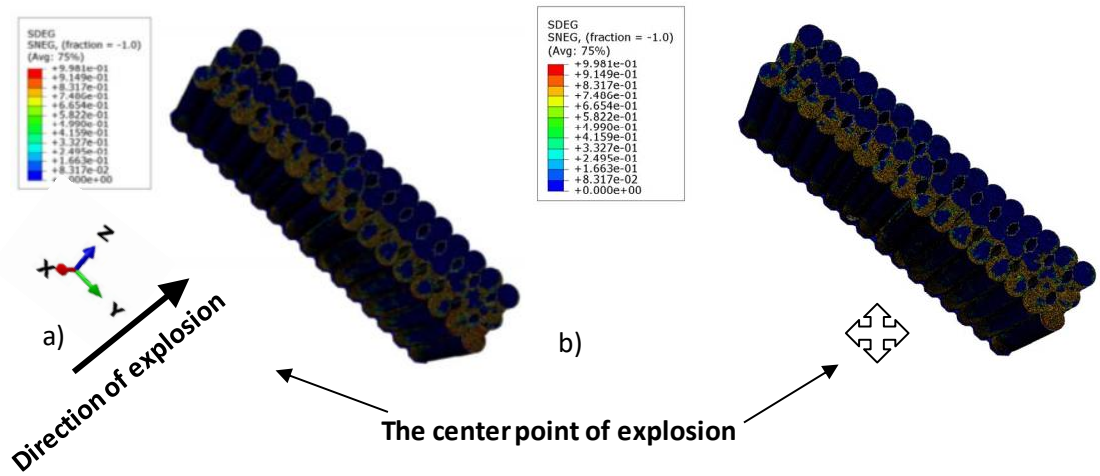

Fig. 26 The SDEG output of the 337.5 tons of TNT simulated cases a) without additional reinforcement and $\mathrm{b}$ ) with additional reinforcement in the ribs between the silos

\subsection{Effect of the Soil and Foundation}

The August 4, 2020 explosion released rapid hot gases and produced high temperature and pressure, i.e. enormous amount of energy in only milliseconds. It formed of a blast wave that not only radiated throughout the city, but it radiated in the unbounded soil domain in a form of spherical type wave. Therefore, to check the contribution of the soil and foundation, an extra simulation consisting of the silos, the pile cap, pile foundation as well as the soil medium was simulated for the estimated 337.5 tons TNT blast magnitude (938 tons of Ammonium Nitrate). The displacements at the head, intermediate and near-bottom of the silos were extracted from the FE model. The geometry and properties of the soil and foundation were extracted from the real 1960s plans and designs (Fig. 11). Fig. 27 shows the FE model in flexible-based condition, consisting of the silos, the grains, the $140 \mathrm{X} 30 \mathrm{~m}$ pile cap, the $250030 \times 30 \mathrm{~cm}$ driven square $15 \mathrm{~m}$ length piles as well as the $460 \mathrm{X} 200 \mathrm{X}$ $17 \mathrm{~m}$ soil medium. In the FE model, and as detailed in Table 2, the pile cap was built using S4R shell elements formed using 7902 elements. Moreover, the pile cap's steel reinforcements were defined as layers of reinforcement as part of the pile cap's shell elements using the rebars command available in Abaqus. Finally, the piles were built using 
B31 beam elements using 17868 elements while the soil medium was built using C3D8R solid elements using 30400 elements (Table 2). The typical Mohr-Coulomb model was used to define the plasticity behavior of the soil medium that is formed of a $2 \mathrm{~m}$ miscellaneous backfill sand material and $15 \mathrm{~m}$ sandy material that presents some levels of gravel and clay (Table 7). In addition, the concrete and steel reinforcements in the silos and pile cap were tied using the tie command in ABAQUS while the silos and the pile cap as well as the pile cap and the piles' interface were modeled by tying the different parts together.

As shown in Fig. 28, that presents the amount of damage the silos exhibited after the blast loading, the numerical results show that in both fixed and flexible-based cases, the first and second row of silos are destroyed while the third row of silos is damaged. Noting that in this row, the last two silos are destroyed (silos 15 and 16). Also, as shown in Fig. 29, silos 4 and 5 exhibit the highest amount of displacement and damage. Therefore, silos 4 and 5 will be used as reference silos in the analysis. The results indicate that, in silos 4 and 5 , the maximum relative displacement (head with respect to bottom) only decreases by a ratio of 0.99 while the permanent relative displacement decreases by a ratio of 0.78 from the fixed to the flexible 337.5 tons TNT case. In addition, the average ratio of the maximum and relative displacement from the fixed to the flexible 337.5 tons TNT case at the head level is equal to 1.0 and 0.77 , respectively. The increase in silos displacement is also detected at the intermediate level. For example, in silos 4 and 5, the maximum relative displacement (intermediate with respect to the bottom) increases by a small ratio of 1.06 while the permanent relative displacement decreases significantly by a ratio of 0.73 from the fixed to the flexible 337.5 tons TNT case. In addition, at the intermediate level for the 337.5 tons TNT, the average ratio of the maximum and relative silos' displacement fixed to the flexible-based cases is equal to 1.06 and 0.71 , respectively.

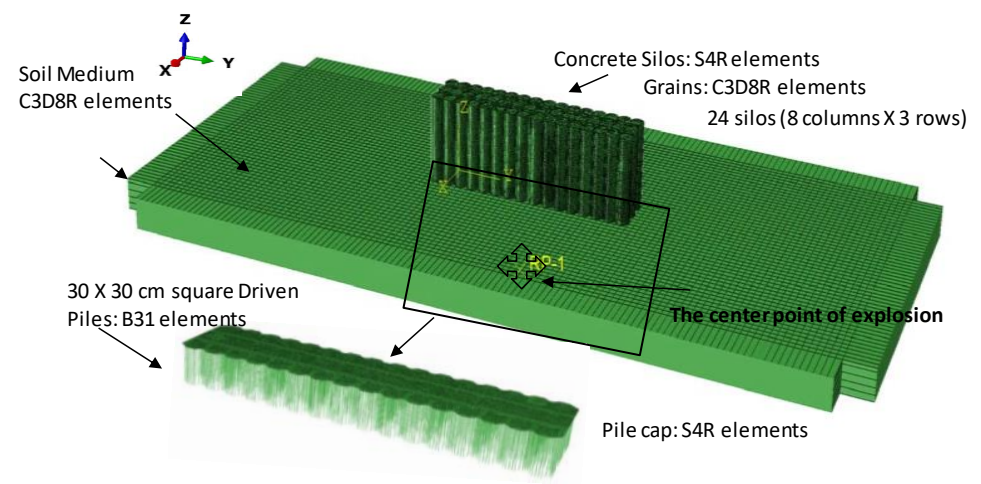

Fig. 27 The FE model (flexible-based model)

Table 7. Soil Properties

\begin{tabular}{ccccccc}
\hline & $\rho\left(\mathrm{kg} / \mathrm{m}^{3}\right)$ & $E(\mathrm{GPa})$ & $v$ & $c(\mathrm{kPA})$ & $\Phi\left(^{\circ}\right)$ & $\psi\left(\left(^{\circ}\right)\right.$ \\
\hline $\begin{array}{c}\text { Backfill Material } \\
\text { Sandy Soil with some levels }\end{array}$ & 1500 & 40 & 0.25 & 2 & 44 & 2.5 \\
of gravel and clay & 1700 & 25 & 0.25 & 10 & 38 & 10 \\
\hline
\end{tabular}




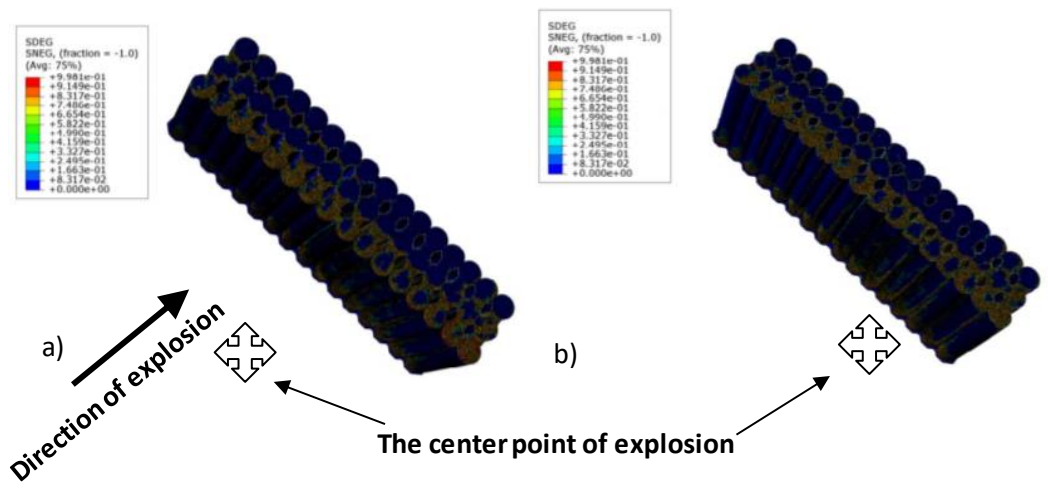

Fig. 28 The SDEG output of the a) fixed and b) flexible-based 337.5 tons of TNT simulated cases
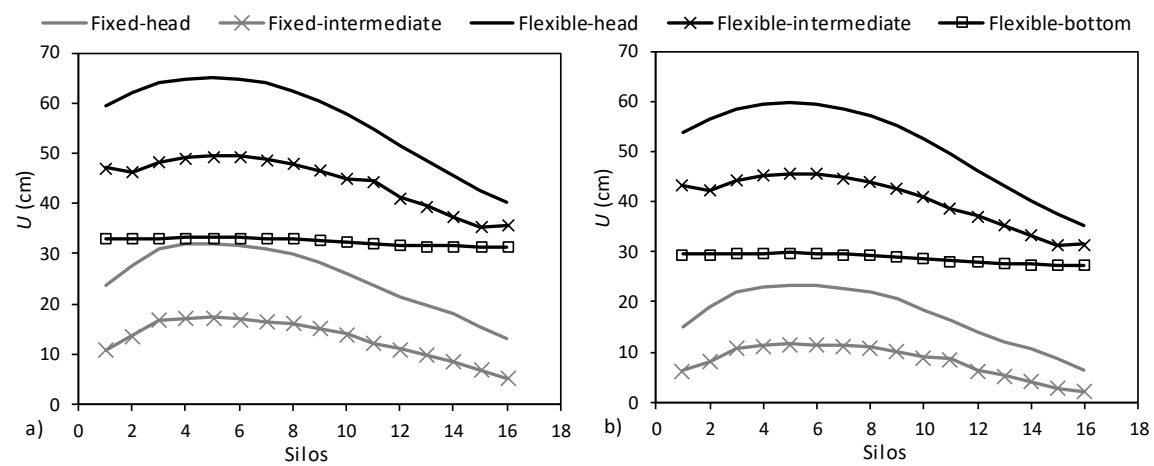

Fig. 29 a) Maximum and b) permanent displacement in the direction of the blast for the 337.5 tons TNT fixed and flexible-based cases

This increase in silos' displacement is caused by the contribution/role played by the soil medium and the pile foundation. Therefore, to examine this contribution, the fixed and flexible numerical models' different types of energies were extracted and compared. The results show that, the decrease in silos' displacement is manifested by a decrease in the amount of strain and damage dissipated energies. These energies decrease by a ratio of 0.82 and 0.78 from the fixed to the flexible-based case, respectively. The strain energy refers to the energy stored in the model while the damage dissipated energy refers to the wasted energy outside the model caused by the blast loading. On the other hand, the total energy released by the model increases by a ratio of 1.32 from the fixed to the flexiblebased case while the internal energy, external work and kinetic energy remain almost the same under both models. As a result, even though the silos exhibit a higher amount of displacement when considering the soil and the foundation, the level of damage is very close compared to the fixed-based modeled case. Therefore, the results indicate that the soil and the foundation played a positive role in the explosion by storing more while dissipating less amount of energies. The flexible model absorbed part of the released energy, which only accounts for $0.033 \%$ of the total energy released by the August 4,2021 explosion. The total energy released by the explosion is equal to $1.84 \mathrm{X} 10^{12} \mathrm{~J}$ (every 1 ton of TNT releases $4.184 \times 10^{9} \mathrm{~J}$ ) while the external work exhibited by the fixed and flexiblebased 337.5 tons TNT case is equal to $590 \times 10^{6} \mathrm{~J}$. This value was calculated by dividing the external work exhibited by the FE model to the explosion released energy. The obtained 
results indicate that the silos' base displace 27 to $30 \mathrm{~cm}$ while the silos' head displace 40 to $65 \mathrm{~cm}$ in the direction of the explosion. These displacements exceed all limits set by design codes such as Eurocode [34,45], indicating that the silos, in the current state cannot be reused.

\section{Conclusions}

The Beirut port silos' damage followed by the August 4, 2020 explosion was assessed using a three-dimensional laser scan and finite element simulations. The 3D scan was performed by the higher school of Engineering "ESIB" at the Saint Joseph University of Beirut in collaboration with the Swiss company "Amman" Engineering while the numerical models were simulated using Abaqus explicit. The effects of the blast magnitude, silos' concrete strength, additional reinforcement and concrete coating added to the silos in 2000, reinforcing the ribs between the silos and the effect of the soil and the foundation were investigated. The damage and silos' displacement obtained from the 3D FE models were compared to the results obtained by the 3D laser scan that were estimated in two phases using two different equipment: the LEICA BLK360 and the Z+F Imager 5010X.

The 752 million points of measure in three dimensions using 25 stations in $360^{\circ}$ panorama infrared images estimated a general tilt of silos between 20 and $30 \mathrm{~cm}$ in the direction of the blast. Therefore, comparing the 3D scan to the FE results allowed a precise estimation of the blast magnitude. A blast magnitude of 337.5 tons TNT (938 tons of Ammonium Nitrate) was found to best capture the 3D scan results and therefore, the real silos' displacement and damage.

The numerical results showed that for low levels of blast magnitude such as 337.5 and 225 tons of TNT, concrete compressive strength does not affect the amount of silos' displacement. Nevertheless, as the magnitude of the blast increases, designing the silos with higher concrete compressive strength decreases their damage amount. Nevertheless, for the 337.5 tons TNT estimation blast magnitude, designing the silos with higher compressive strength would not have affected the amount of damage obtained after the August 4, 2020 explosion.

The FE results indicated that the silos with no additional reinforcement and concrete coating (ARC) added from 2000 to 2002 exhibit lower displacement and higher amount of damage (in compression and tension) for blast magnitudes greater than 337.5 tons TNT compared to the "with ARC" cases. Nevertheless, for the estimated blast case (337.5 tons TNT), the amount of damage exhibited in the silos is greater in the case of "no ARC" compared to the "with ARC" case. As a result, reinforcing the outer silos from 2000 to 2002 played a positive role in the blast by decreasing the amount of the silos' damage.

The obtained results proved that if the ribs of the silos were reinforced like the ARC from 2000 to 2002, this reinforcement would have played a positive role in decreasing the amount of silos' displacement and damage and by absorbing a small part of the released energy. Reinforcing the ribs would have decreased the displacement at the head of the silos by $20 \%$.

As for the soil and the foundation, the results pointed out to the positive role they played in the blast. The flexible model absorbed part of the explosion released energy. Even though the level of damage was very close in the fixed and the flexible models, the presence of the soil and the foundation caused an increase in silos' displacements. This increase was manifested by a decrease in the amount of strain and dissipated energies exhibited by the numerical model.

Finally, the 3D scan and FE results showed that the silos' base displaced 27 to $30 \mathrm{~cm}$ while the silos' head displace 40 to $65 \mathrm{~cm}$ in the direction of the explosion. Thus, the silos 
displaced 20 to $30 \mathrm{~cm}$ in the direction of the blast. These displacements exceed all limits set by design codes, indicating that the silos, in the current state cannot be reused.

\section{Acknowledgement}

The authors would like to acknowledge the support of the Lebanese authorities, Lebanese Army as well as the assistant of the USJ-ESIB-ASCE student chapter, Francois Karam for the drone pictures and Miguel Bandera for the 3D modeling and photogrammetry.

\section{References}

[1] Tang Q, Jiang N, Yao Y, Zhou C, Luo X, Wu T. Safety assessment of buried gas pipeline subject to surface explosion: A case study in Wuhan. China. Engineering Failure Analysis, 2021, 120: 105119. https://doi.org/10.1016/i.engfailanal.2020.105119

[2] Luccioni BM, Ambrosini RD, Danesi RF. Analysis of building collapse under blast loads. $\begin{array}{lll}\text { Engineering } \quad \text { Structures, } & \text { 26:63-71. }\end{array}$ https://doi.org/10.1016/i.engstruct.2003.08.011

[3] Osteraas JD. Murrah building bombing revisited: a qualitative assessment of blast damage and collapse patterns. Journal of Performance in Construction Facility, 2006, 20:330-5. https://doi.org/10.1061/(ASCE)0887-3828(2006)20:4(330)

[4] Raphael W, Faddoul R, Feghaly R, Chateauneuf A. Analysis of Roissy airport Terminal 2E collapse using deterministic and reliability assessments. Engineering Failure Analysis, 2012, 20 :, 1-8. https://doi.org/10.1016/j.engfailanal.2011.10.001

[5] Raphael W, Zgheib E, Chateauneuf A. Experimental investigations and sensitivity analysis to explain the large creep of concrete deformations in the bridge of Cheviré. Case Studies in Construction Materials, 2018, 9: e00176. https://doi.org/10.1016/j.cscm.2018.e00176

[6] Raphael W, Faddoul R, Geara F, Chateauneuf A. Improvements to the Eurocode 2 shrinkage model for concrete using a large experimental database. Structural Concrete, 2012, 13: 174-181. https://doi.org/10.1002/suco.201100029

[7] Kawashima K, Takahashi Y, Ge H, Wu Z, Zhang J. Reconnaissance report on damage of bridges in 2008 Wenchuan, China, earthquake. Journal of Earthquake Engineering, 2009, 13: 956-998. https://doi.org/10.1080/13632460902859169

[8] Mendez D. Stunned Salvador suffers second deadly quake in a month, The BG News, http://media.www.bgnews.com/media/storage/paper883/news/2001/02/14/Worl d/Stunned.Salvador. Suffers Second Deadly Quake In A Month-1283510.shtm, 2001 (accessed Jan. 22, 2008).

[9] Ozmen HB. A view on how to mitigate earthquake damages in Turkey from a civil engineering perspective, Journal of Research on Engineering Structures and Materials, 2021, 7(1): 1-11. https://doi.org/10.17515/resm2020.231ea1113ed

[10] After the blast: Satellite images show destruction in Beirut, The Washington Post, https://www.washingtonpost.com/world/2020/08/05/beirut-explosions-satelliteimages-destruction/?arc404=true, 2020 (accessed August 5, 2020).

[11] Beirut explosion: Legendary Palestinian banker envisaged silos that shielded his adopted city from more destruction, The National News, https://www.thenationalnews.com/world/beirut-explosion-legendary-palestinianbanker-envisaged-silos-that-shielded-his-adopted-city-from-more-destruction1.1061359\#5, 2020 (accessed August 12, 2020).

[12] Lebanon's government nears collapse as anger over blast surges, Bloomberg, https://www.bloomberg.com/news/articles/2020-08-09/global-magnitudes-pledgeaid-to-lebanon-after-beirut-blast, 2020 (accessed August 9, 2020).

[13] Stephens, HW. The Texas City Disaster 1947, University of Texas Press, Texas, USA, 1997. 
[14] Mannan S. Lees' Loss Prevention in the Process Industries. Hazard Identification, Assessment and Control, Elsevier, Third Ed., Oxford, United Kingdom, 2005.

[15] Mainiero RJ, Rowland JH. A review of recent accidents involving explosives transport, National Institute for Occupational Safety and Health (NIOSH), Pittsburgh Research Laboratory, 2007.

[16] REPORT 2013-02-I-TX, U.S. chemical safety and hazard investigation board, investigation report, West fertilizer company fire and explosion, 2016.

[17] Li X, Hoseki H. Study on the contamination of chlorides in ammonium nitrate, Process Safety and Environmental Protection, 2005, 83: 31-37. https://doi.org/10.1205/psep.04060

[18] Marlair G, Kordek M. Safety and security issues relating to low capacity storage of ANbased fertilizers. Journal of Hazardous Materials, 2005, 123: 13- 28. https://doi.org/10.1016/i.jhazmat.2005.03.028

[19] DIRECTIVE 2012/18/EU, The control of major-accident hazards involving dangerous substances, amending and subsequently repealing Council Directive 96/82/EC, 2012.

[20] Scott G, Stanley G. Ammonium Nitrate: Its Properties and Fire and Explosion Hazards, U.S. Department of the Interior, Bureau of Mines,1948.

[21] Explosion in a nitrogenous fertilizer plant 21 September 1921, Oppau, Germany, $\mathrm{N}^{\circ}$ 14373, French Ministry of Environment, March 2008, https://www.aria.developpement-durable.gouv.fr/wpcontent/files_mf/FD_14373_oppau_1921_ang.pdf.

[22] Inquiry Report Department of Mining and Petroleum, Government of Papua New Guinea, 1994.

[23] Tianjin Port Accident Investigation Report, The State Council of the People's Republic of China, 2016.

[24] Bauer A, King A, Heater R. The detonation properties of ammonium nitrate perils, Department of Mining and Engineering, Queens University, Canada, 1978.

[25] King A, Bauer A, Heater R. The explosion hazards of ammonium nitrate and ammonium nitrate based fertilizer compositions, Department of Mining and Engineering, Queen's University report to the Canadian Fertilizer Institute and Contributing Bodies, Canada, 1982.

[26] Joint Research Centre JRC, Summary Report, Workshop on Ammonium Nitrate, Joint Research Centre, European Commission, Ispra, Italy, 2002.

[27] Nguyen TA, Nguyen PT, Do ST. Application of BIM and 3D laser scanning for quantity management in construction projects. Advances in Civil Engineering, 2020,8839923. https://doi.org/10.1155/2020/8839923

[28] Farahani, N, Braun A, Jutt D, Huffman T, Reder N, Liu Z, Yagi Y, Pantanowitz L. Threedimensional imaging and scanning: current and future applications for pathology. Journal of Pathology Informatics, 2017, 8: 36. https://doi.org/10.4103/jpi.jpi_32_17

[29] Haddad NA. From ground surveying to 3D laser scanner: A review of techniques used for spatial documentation of historic sites. Journal of King Saudi University Engineering Sciences, 2011, 23: 109-118. https://doi.org/10.1016/i.jksues.2011.03.001

[30] Z+F IMAGER 5010X, https://www.zf-laser.com/Z-F-T-Cam.150.0.html?\&L=1.

[31] Leica BLK360 Imaging Laser Scanner, https://leica-geosystems.com/products/laserscanners/scanners/blk360.

[32] Sadek S, Dabaghi M, Elhajj I, Zimmaro P, Hashash Y, Yun S, O'Donnell T, Stewart J. A report of the NSF-Sponsored geotechinical extreme event reconnaissance association in collaboration with the American University of Beirut, REPORT GEER-070, 2020, https://doi.org/10.18118/G6C96C.

[33] Hafezolghorani ME, Hijazi F, Vaghei R. Simplified damage plasticity model for $\begin{array}{lllll}\text { concrete. Structural } & \text { Engineering Journal, }\end{array}$ https://doi.org/10.2749/101686616X1081 
[34] Eurocode 4, Actions on structures, EN 1991-4, 2006.

[35] The Beirut Port Explosion, Forensic Architecture, https://forensicarchitecture.org/investigation/beirut-port-explosion, 2020 (accessed 16 November 2020).

[36] Alonso FD, Ferradas EG, Perez JFS, Aznar AM, Gimeno JR, Alonso JM. Characteristic overpressure-impulse-distance curves for the detonation of explosives, pyrotechnics or unstable substances. Journal of Loss Prevention. in the Process Industries, 2006, 19: 724-728. https://doi.org/10.1016/j.jlp.2006.06.001

[37] HSE, Safety Report Assessment Guide: Chemical warehouses - Hazards, Health and Safety Executive, United Kingdom, 2012.

[38] Cooper PW. Comments on TNT Equivalence. Proceedings of 20th Pyrotechnic Seminar, Colorado Springs, Colorado, USA, 1994.

[39] Locking PM. The Trouble with TNT Equivalence. Proceedings of the 26th International Symposium on Ballistics, Miami, USA, 2011.

[40] HSE, Storing and Handling Ammonium Nitrate, Health and Safety Executive, United Kingdom, 2004.

[41] GHD, Orica Mining Services, Report for Kooragang Island Facility Uprate, PHA MOD1 Report, Australia, 2012.

[42] Kersten RJA, Mak WA. Explosion hazards of ammonium nitrate, how to assess the risks. Proceedings of the International Symposium on Safety in the Manufacture, Storage, Use, Transport and Disposal of Hazardous Material, Tokyo, Japan, 2004.

[43] Nygaard EC. Storage of technical (porous) ammonium nitrate, International Society of Explosives Engineers, 2008.

[44] Krauthammer T. Modern Protective Structures, CRC Press, Taylor \& Francis Group, 2008. https://doi.org/10.1201/9781420015423

[45] Eurocode 2, Design of concrete structures, EN 1992-1-1, 2004.

[46] Rigby SE, Lodge TJ, Alotaibi S, Barr AD, Clarke SD, Langdon GS, Tyas A. Preliminary yield estimation of the 2020 Beirut explosion using video footage from social media. Shock Waves, 2020. https://doi.org/10.1007/ s00193-020-00970-z

[47] Diaz J. Explosion analysis from images: Trinity and Beirut, arXiv preprint, 2020, arXiv:2009.05674. https://doi.org/10.1088/1361-6404/abe131

[48] Aouad C, Chemissany W, Mazzali P, Temsah Y, Jahami A. Beirut explosion: Energy yield from the fireball time evolution in the first 230 milliseconds , arXiv preprint, 2020, arXiv:2010.13537.

[49] Stennett C, Gaulter S, Akhavan J. An estimate of the TNT-equivalent net explosive quantity (NEQ) of the Beirut Port explosion using publicly-available tools and data, Propellants, Explosives, Pyrotechnics. 2020, 45: 1675-1679. https://doi.org/10.1002/prep.202000227

[50] Pasman H, Fouchier C, Park S, Quddus N, Laboureur D. Beirut ammonium nitrate explosion: Are not we really learning anything. Journal of Process Safety, 2020, 39: e12203. https://doi.org/10.1002/prs.12203

[51] Valsamos G, Larcher M, Casadei F. Beierut explosion 2020: A case study for a largescale urban blast simulation. Journal of Safety Science, 2021, 137:105190. https://doi.org/10.1016/i.ssci.2021.105190

[52] Na-Hyun Y, Jang-Ho JK, Tong-Seok H, Yun-Gu C, Jang HL. Blast-resistant characteristics of ultra-high strength concrete and reactive powder concrete. Journal of Construction and Building Materials, 2012, 28: 694-707. https://doi.org/10.1016/i.conbuildmat.2011.09.014 